\title{
PROPUESTAS PARA LA REGULACIÓN DEL TRIBUNAL DE CONTRATACIÓN PÚBLICA. ORGANIZACIÓN, COMPETENCIA Y PROCEDIMIENTO*
}

\author{
Alejandro Vergara Blanco \\ Universidad Católica de Chile \\ Daniel Bartlett Burguera \\ Universidad Católica de Chile
}

\begin{abstract}
RESUMEN: Los autores analizan los aspectos críticos relativos a la organización, competencia y procedimiento que con mayor énfasis han sido discutidos respecto del Tribunal de Contratación Pública, órgano jurisdiccional especial creado para la resolución de las contiendas entre particulares y los organismos públicos en el contexto de las licitaciones públicas. Tras revisar distintas propuestas de optimización legislativa relacionadas con el tribunal, discutidas en reuniones de trabajo y evaluaciones del sistema de compras públicas actual, los autores aportan algunas soluciones adicionales que pueden contribuir a mejorar su desempeño.

Palabras Clave: modernización del Estado, justicia administrativa, tribunal especial, contratación administrativa.

RECIBIDO: mayo 2017; ACEPTADO: julio 2017.
\end{abstract}

Alejandro Vergara Blanco. Profesor titular de derecho administrativo en la Facultad de Derecho de la Pontificia Universidad Católica de Chile (PUC). Director del Programa de Derecho Administrativo Económico de la misma facultad. Email: alvergar@uc.cl.

Daniel Bartlett Burguera. Abogado. Investigador del Programa de Derecho Administrativo Económico de la Facultad de Derecho PUC. Email: dbartlett@uc.cl.

* Los autores agradecen las observaciones, comentarios y sugerencias realizadas por los árbitros anónimos de Estudios Públicos. 


\title{
PROPOSALS FOR REGULATING CHILE'S PUBLIC PROCUREMENT TRIBUNAL. ORGANIZATION, POWERS AND PROCEDURES
}

\begin{abstract}
The authors analyse the most intensively discussed critical aspects of the organization, powers and procedures of the Public Procurement Tribunal, a specialized judicial body set up to resolve disputes between private individuals and public bodies arising out of the public tendering process. After reviewing some proposals for optimizing Tribunal-related legislation that have been discussed at working meetings and in evaluations of the current public procurement system, they offer some further solutions that could help to enhance its performance.

KeYwords: State modernization, administrative justice, specialized tribunal, public procurement.

ReCEIVED: May 2017; ACCEPTED: July 2017.
\end{abstract}

\section{INTRODUCCIÓN}

a administración pública chilena, a través de su plataforma electrónica www.mercadopublico.cl (parte esencial del sistema de compras públicas), durante 2013 logró congregar a 850 organismos públicos y 118.000 proveedores, transando un total de US\$ 9.505 millones, de los cuales, cerca de US\$ 4.209 millones tuvo como destino el sector empresarial micro y pequeño (44 por ciento). Por su parte, los indicadores de la Dirección de Compras y Contratación Pública respecto al primer semestre del 2016, señalaron un crecimiento del 14,1 por ciento respecto del mismo trimestre el año $2015 .{ }^{1}$

De estas cifras podemos desprender la enorme importancia que reviste la contratación que realiza la administración y su impacto en la economía del país. En esta materia no sólo pareciera ser relevante lo relacionado con la forma en que se gastan los recursos públicos, sino también su efecto en la generación de empresas o proveedores de diversos tamaños, que en su conjunto mueven buena parte de la economía.

La transparencia y competitividad mejoran con la existencia de reglas claras, justas y preestablecidas, de un ordenamiento jurídico que ga-

${ }^{1}$ Fuente: ChileCompra, Plan Estratégico (2014-2018). Consultar www.chilecompra.cl. Se conoce coloquial y oficialmente a la Dirección de Compras y Contratación Pública (DCCP) como "ChileCompra". De hecho, el mismo sitio web de la dirección utiliza este nombre abreviado. 
rantice y asegure a todas las personas la igualdad de acceder y participar como proveedores de la administración, acompañado de un sistema de control y reclamación eficientes y expeditos, son elementos claves para alcanzar un sistema de contratación administrativa exitoso. Ello permite una actuación coordinada y eficiente por parte de la administración, disminuyendo tanto los costos de adquisición, por medio de la licitación pública, que es un proceso abierto y competitivo, como también los costos de transacción, entregando información de manera más completa, fácil y directa a través de medios tecnológicos. A la vez, esto permite a todos los agentes económicos tomar conocimiento, participar de los procesos y cooperar en el control de su buen funcionamiento.

Una nueva institucionalidad nace en 2003 con la dictación de la Ley 19.886, de Bases sobre Contratos Administrativos de Suministro y Prestación de Servicios, ${ }^{2}$ conocida en la práctica como Ley de Compras Públicas o Ley de Compras. Ella representó un gran avance no sólo en materia de modernización de la administración del Estado, sino que también en lo relacionado con la transparencia y probidad de la actuación estatal. Fueron claves para avanzar con paso firme y cumplir con sus tareas el establecimiento de una normativa general en materia de contratación, una nueva institucionalidad orgánica y una plataforma electrónica. Todo ello ha representado una evolución importante, se ha generado una valiosa experiencia práctica y administrativa del nuevo sistema de contratación administrativa y ha producido una literatura no demasiado numerosa, pero creciente en los últimos años, sobre todo dirigida a analizar los diversos aspectos de la gestión y de la contratación propiamente tal. ${ }^{3}$

${ }^{2}$ Ley 19.886 de 30 de julio de 2003, "Bases sobre contratos administrativos de suministro y prestación de servicios", República de Chile.

${ }^{3}$ En Chile no teníamos hasta 2003 el desarrollo que es notorio en la literatura de derecho comparado; puede verse al respecto en dos países de sistemas similares: para Argentina, Juan Carlos Cassagne, El contrato administrativo (Buenos Aires: Abeledo Perrot, 2009); Juan Carlos Cassagne, "Actuales desafíos y clásicos dilemas de la contratación administrativa", en Derecho administrativo. Innovación, cambio y eficacia. (Lima: Thomson Reuters, 2014): 191-201; para Francia: Frank Moderne, "La contratación pública en el derecho administrativo francés contemporáneo", en La contratación pública, editado por Juan Carlos Cassagne y Enrique Rivero Yserrn (Buenos Aires: Hammurabi, 2006), 253-274. En el caso de la literatura chilena, véase en la bibliografía los aportes más actuales de: Fabián Huepe Artigas, José Luis Lara Arroyo, Luis Eugenio García-Huidobro Herrera, Claudio Moraga Klenner, Natalia Muñoz Chiu, Jenny Nicólas Turrys, Dorothy Pérez Gutiérrez, Francisco Pinilla Rodríguez, Andrés Ruiz Ibáñez, entre otros, dirigidos al análisis de las instituciones jurídicas de fondo, y no a la organización, que es el foco de este escrito. 
El nuevo sistema de contratación administrativa, entonces, no sólo consistió en una nueva definición de materias de fondo, como la licitación y el contrato administrativo (en el cual existía una precaria bibliografía jurídica en nuestro país), sino también en una nueva organización administrativa y jurisdiccional. En efecto, se produjo en 2003 la creación ex novo de los dos siguientes órganos:

a) La Dirección de Compras y Contratación Pública o, más simple, Dirección de Compras, un órgano administrativo específico y descentralizado, encargado de la gestión y contratación pública. Pese a ser un servicio público descentralizado, está sometido a la supervigilancia del Presidente de la República. No es el foco de nuestro actual trabajo, pero quizás cabría analizar la posibilidad de transformarla en una autoridad administrativa independiente. ${ }^{4}$

b) El Tribunal de Contratación Pública (TCP). Éste es un nuevo órgano jurisdiccional, creado para la resolución de las contiendas entre particulares y los organismos públicos en el contexto de las licitaciones públicas.

En este trabajo no analizamos completamente las bases institucionales, organización, competencia y procedimiento de este órgano, ${ }^{5}$ sino que nuestro foco, más descriptivo que analítico, está dirigido a las propuestas de políticas públicas o de eventuales cambios regulatorios. El objetivo es ofrecer una panorámica sobre todos los temas que se han abordado (doctrina, jurisprudencia, informes oficiales y práctica del tribunal), sin perjuicio de detenerse en algunos puntos que consideramos de mayor importancia. En efecto, analizamos los aspectos críticos relativos a la organización, competencia y procedimiento que con mayor énfasis han sido discutidos respecto del Tribunal de Contratación

${ }^{4}$ La propuesta de cambio institucional y transformación de la Dirección de Compras en una autoridad administrativa independiente o agencia autónoma la realiza en otro trabajo uno de los autores. Véase Alejandro Vergara, "Autoridades independientes y ordenación de la contratación administrativa", en Contratos públicos, problemas, perspectivas y prospectivas. XVIII Jornadas internacionales de derecho administrativo (Colombia: Universidad Externado de Colombia, 2017).

${ }^{5}$ Para evitar repeticiones y desarrollos más amplios que habrían abultado este trabajo, nos remitimos a una descripción del TCP y recuento de la bibliografía respectiva realizado por uno de los autores en Alejandro Vergara, "Tribunal de Contratación Pública. Bases institucionales, organización, competencia y procedimiento", Revista de Derecho de la Pontificia Universidad Católica de Valparaíso (2016): 352-353. 
Pública. Seguidamente, tras revisar otras propuestas de optimización legislativa relativas al tribunal, discutidas en reuniones de trabajo y evaluaciones del actual sistema de compras públicas, señalamos algunas propuestas adicionales que puedan contribuir a la mejora de su funcionamiento.

El presente artículo, entonces, tiene por objeto, en primer lugar, realizar un repaso sobre la actual regulación del TCP, desde la perspectiva de los cambios realizados por vía de modificaciones normativas; lo que han señalado informes de distintos organismos, así como indicar las propuestas oficiales de cambios entre 2015 y 2017. En segundo lugar, realizar una mirada al derecho comparado (España), para mostrar algunos aspectos que consideramos de interés en relación con la resolución especializada de conflictos en materia de contratación pública. En tercer, cuarto y quinto lugar, señalar propuestas de mejora sobre aspectos de la organización, competencia y procedimiento del tribunal que se han ido observando desde su creación, las que además serán imbricadas con algunas propuestas adicionales y comentarios críticos.

\section{CREACIÓN Y ACTUAL REGULACIÓN DE UN TRIBUNAL HIIPER ESPECIALIZADO}

El TCP fue creado en 2003, y fue el primer ejemplo de jurisdicción híper especializada en nuestro país, para luego haber sido objeto de algunas modificaciones legales, algunas dadas por la práctica de éste y otras, por mejoras regulatorias.

\subsection{Creación y actual funcionamiento del Tribunal de Contratación Pública}

La aprobación de la Ley de Compras, como se indica, trajo consigo la creación de un órgano resolutorio de conflictos en materia de licitaciones públicas, el Tribunal de Contratación Pública (TPC), según su denominación legal. ${ }^{6}$

${ }^{6}$ Regulado en el capítulo V de la Ley 19.886. En cuanto a los aspectos de funcionamiento y organización, se rige por el auto acordado de la Corte Suprema de 11 de marzo de 2011, texto refundido, Acta n. ${ }^{\circ}$ 16-2011. 
De forma pionera, éste fue el primer órgano originado al amparo de la actual línea legislativa que opta — desde hace más de una década - por un modelo de justicia administrativa fraccionada y especializada, la que dejó atrás el antiguo anhelo de crear unos tribunales de lo contencioso-administrativo con competencia general para el conocimiento de los asuntos entre personas físicas o jurídicas, y la administración del Estado.

Esta tendencia responde al modelo regulatorio económico implementado en Chile a partir de la Constitución de 1980, que redefinió los roles asignados a los particulares y a la administración en variadas actividades económicas relevantes, el cual evidencia la necesidad de crear tribunales especiales, dentro o fuera del poder judicial, para una resolución más ajustada de las contiendas que se generen en torno a este escenario. ${ }^{7}$

De esta manera, el fenómeno mixto de justicia administrativa chileno se completaría a partir del siguiente esquema: ${ }^{8}$

a) La responsabilidad patrimonial de la administración queda sujeta al proceso ordinario (primera instancia, apelación y eventual casación).

b) El contencioso anulatorio queda dividido en tres órdenes:

—En la década de 1980, se creó el recurso de protección, como sustituto incompleto de justicia administrativa.

—En la década de 1990, se crearon múltiples acciones especiales (bajo la denominación de "recursos") sustanciados ante las respectivas Cortes de Apelaciones.

-Por último, en la década de los 2000, se empezaron a crear tribunales con competencia administrativa respecto a ámbitos muy concretos y especializados; marco en el que se ubica el TCP.

La filosofía detrás de la creación de estos tribunales especiales es la de proveer un sistema de resolución de controversias más preciso y adecuado a las tecnicidades de cada sector. Por ello están conformados

7 Véase una descripción de tal tendencia en Alejandro Vergara, "El nuevo paradigma de jurisdicción administrativa pluriforme e híper especializada. Crónica de una espera, como la de Godot", en Anuario de Derecho Público UDP (Santiago: Universidad Diego Portales, 2014), 269-271; y en Alejandro Vergara, "La tendance actuelle du droit chilien pour une juridiction administrative hyper-spécialisée", en Mélanges en l'honneur de Pierre Bon (Paris: Éditions Dalloz, 2014), 126-140.

${ }^{8}$ Vergara, "El nuevo paradigma". 
por especialistas altamente capacitados, con experiencia comprobada en las materias objeto de revisión; los que además debieran contar con independencia y autonomía tanto de la administración del Estado como de los particulares en la toma de decisiones.

En efecto, la ausencia de unos tribunales u órganos concretos para el conocimiento de este tipo de contiendas hasta la reforma constitucional de 1989, que eliminó la referencia a los tribunales contencioso-administrativos del artículo 38 de la Constitución, alejó indefinidamente la posibilidad de contar con una justicia específica y unitaria para este ámbito, así como tampoco implementó procedimiento contencioso-administrativo alguno, al abrírsele la competencia en este campo a la justicia ordinaria, ${ }^{9}$ la que sigue un extenso procedimiento de lato conocimiento.

Ante este escenario jurisdiccional, la importancia de la contratación pública como sector relevante para la actividad económica del país exigió la necesidad de un sistema de resolución de conflictos eficaz, especializado, útil y que asegure la ponderación de los distintos intereses en juego. El TCP, como órgano especialmente garante de la legalidad de los procedimientos licitatorios, si bien entró en funcionamiento el año 2005, a partir del 2011 experimentó un incremento en el ingreso de causas, las que desde entonces nunca bajan de 252 , tal como muestra la tabla $1 .^{10}$

Todo lo anterior revela la importancia creciente de contar con un buen sistema de justicia administrativa en el campo de la contratación pública, que asegure, tanto a los licitadores como a los usuarios finales de la ejecución de los respectivos contratos, el cumplimiento de unos estándares mínimos de legalidad y transparencia en estos procedimientos.

En fin, esta nueva instancia jurisdiccional híper especializada ha estado alejada de la tradicional acusación de activismo o deferencia, como ha sido el caso de la jurisdicción ordinaria. ${ }^{11}$

\footnotetext{
${ }^{9}$ Así, Urbano Marín, "Vigencia actual de la invalidación de los actos administrativos", Revista de Derecho del Consejo de Estado 2 (2002): 4.

${ }^{10}$ Fuente: Transparencia ChileCompra.

${ }^{11}$ Según argumenta uno de los autores de este trabajo en Alejandro Vergara, "Los jueces en la era del derecho democrático. Especialización y principios, en la superación del activismo y la deferencia”, Temas de la Agenda Pública 83 (2015): 12, Centro de Políticas Públicas UC.
} 
Tabla 1. INGRESO DE CAUSAS POR AÑO AL TPC (2005-2016)

\begin{tabular}{rr}
2005 & 46 \\
2006 & 100 \\
2007 & 90 \\
2008 & 98 \\
2009 & 166 \\
2010 & 169 \\
2011 & 282 \\
2012 & 268 \\
2013 & 314 \\
2014 & 326 \\
2015 & 351 \\
2016 & 252 \\
\hline
\end{tabular}

1.2. Mejoras al funcionamiento del TCP incorporadas por modificaciones legislativas, reglamentarias y por la práctica

Variadas han sido las mejoras al TCP, algunas incorporadas por vía de modificaciones legislativas y otras resultantes de la praxis del tribunal.

i) Modificaciones legales

Pese al gran número de críticas anteriormente identificadas sobre el funcionamiento de este tribunal —más adelante las señalaremos—, resulta llamativo que hasta la fecha solo una modificación legal haya ido encaminada a resolver un problema, si bien de no menor importancia: el relativo a la notable acumulación de trabajo. ${ }^{12}$

Efectivamente, sobre las audiencias del TCP cabe distinguir dos etapas:

- Hasta diciembre de 2015. De conformidad con el artículo 7 del auto acordado, las audiencias del tribunal se celebraban los días martes y jueves de cada semana y, de forma excepcional, según el volumen y necesidades de trabajo, podía añadírsele una audiencia semanal extraordinaria, por acuerdo del TCP.

-Actualmente. El 2 de diciembre de 2015 se publicó la Ley $20.883,{ }^{13}$ que entre otras cosas, aumentó las sesiones del TCP de 12 al

${ }^{12}$ El propio tribunal se refirió a este aspecto en su cuenta pública. Tribunal de Contratación Pública: Primera cuenta pública, 2012, 7.

${ }^{13}$ Ley 20.883 de 2015, que otorga reajuste de remuneraciones a los trabajadores del sector público, concede aguinaldos que señala y concede otros beneficios que señala. Véase Diario Oficial, 2 de diciembre de 2015. 
mes a 21, con un mínimo de una sesión diaria. También se optimizó la función de los jueces suplentes. Para lo primero, se modificó el inciso $6^{\circ}$ del artículo 22, y para lo segundo, se añadió un inciso $7^{\circ}$. tores. $^{14}$

Este punto venía siendo recurrentemente criticado por varios au-

ii) Modificaciones reglamentarias

En lo referido a las modificaciones reglamentarias, el propio TCP solicitó a la Corte Suprema la posibilidad de mejorar el procedimiento en caso de que el licitador demandante tuviera domicilio fuera del asiento del tribunal, esto es, en regiones. Hasta 2011, el auto acordado de la Corte Suprema que reglamenta los aspectos del artículo 22 de la Ley de Compras, relativos a la organización del TCP, únicamente contemplaba en su artículo 11 la previsión que, para interponer demanda fuera del asiento del tribunal, debía presentarse ante la intendencia regional o la gobernación provincial del domicilio del demandante. La última refundición del citado auto, obedeció a la modificación de su artículo $11,{ }^{15}$ permitiéndose que el TCP pudiera exhortar al juez civil del domicilio del demandante, a fin de practicar las diligencias probatorias fuera de la ciudad de Santiago, además de otras medidas de carácter administrativo conducentes a una mayor agilización del procedimiento.

iii) Mejoras del funcionamiento derivadas de la práctica del tribunal

La práctica habitual del TCP desde 2005 ha permitido la incorporación de varias mejoras que optimizan su funcionamiento. A continuación indicamos algunas:

a) Suspensión del plazo para interponer demanda ante el TCP por presentación previa de recurso de reposición. El plazo para interponer

${ }^{14}$ José Luis Lara y Luis Eugenio García-Huidobro, “Aspectos críticos de la solución de controversias en la Contratación Administrativa bajo la Ley 19.886: El caso del Tribunal de Contratación Pública", en Procedimiento administrativo y contratación pública. Estudios a diez años de la entrada en vigencia de las leyes 19.880 y 19.886, coordinado por José Luis Lara y Gabriel Bocksang (Santiago: Legal Publishing \& Thomson Reuters, 2013); Eduardo Escanilla, "El Tribunal de Contratación Pública en Chile. Un análisis crítico propositivo", Derecho Público Iberoamericano 2 (2013): 103-149; Yuri Antonio Vásquez y Maximiliano Koch, Institucionalidad, procedimiento y jurisprudencia del Tribunal de Contratación Pública. Análisis jurisprudencial desde su establecimiento hasta la actualidad. Memoria para optar al grado de licenciado en ciencias jurídicas y sociales (Santiago: Universidad de Chile, 2014).

${ }^{15}$ Por vía del Acta n. ${ }^{\circ}$ 7-2011 de la Corte Suprema. Ver comentario en Tribunal de Contratación Pública, Primera cuenta pública, 11. 
demanda ante el TCP es de diez días hábiles contados desde el momento de conocer el acto u omisión que se impugna o desde su publicación. Este plazo es fatal, de acuerdo a lo indicado por la ley. No obstante, el tribunal ha entendido que el recurso de reposición que pudiera interponerse contra el organismo licitante, suspende este plazo, ${ }^{16}$ por aplicación del artículo 54 de la Ley 19.880 .

b) Uso de varios mecanismos para optimizar el impulso del procedimiento. De acuerdo a la naturaleza breve y sumaria del proceso que se sigue ante el TCP (art. 27 in fine Ley de Compras), se convierte en una necesidad el hecho de utilizar todos los mecanismos legales posibles conducentes a agilizar la tramitación del procedimiento ante el TCP, o cuanto menos, para, en caso de que fuera legalmente procedente, reanudar la licitación pública cuyo acto o actos se hubieran impugnado. Este órgano ha afirmado la utilización de varias herramientas procesales para ello, como son las siguientes:

- acogimiento de las figuras procesales civiles del desistimiento, el abandono del proceso o el allanamiento; ${ }^{17}$

- archivo de la causa al constatar, una vez abierto el proceso, falta de existir controversia entre las partes; ${ }^{18}$

-llamado a conciliación entre las partes; ${ }^{19} \mathrm{y}$

-otras medidas de impulso del procedimiento.

Según se indicaba en la primera cuenta pública del tribunal, parte importante de la duración del proceso tiene su origen en la falta de impulso procesal de las partes cuando les corresponda. ${ }^{20}$ Para ello, su actual presidente, señalaba el establecimiento de medidas como la siguiente: "El tribunal impulsa el proceso hasta la dictación de la resolución que recibe la causa a prueba, luego el demandante debe notificar por cédula dicha resolución, según establece el Código de

16 Tribunal de Contratación Pública, Primera cuenta pública, 5-6. Véase por ejemplo la sentencia dictada por el TCP "Ely Lilly de Chile Limitada con Servicio de Abastecimiento del Sistema Nacional de Servicios de Salud" (2006).

17 Tribunal de Contratación Pública, Primera cuenta pública 6. Sobre allanamiento ver por ejemplo la sentencia del TCP "Centro de Gestión Ambiental y Servicios Crecer Limitada con Ilustre Municipalidad La Granja” (2012).

${ }^{18}$ Véase las sentencias del TCP: "Aseo y Servicios Industriales Limitada con Instituto de Previsión Social” (2013) y "Centro de Gestión Ambiental y Servicios Crecer Limitada con Ilustre Municipalidad La Granja" (2012).

${ }^{19}$ Como señala Vergara, "Tribunal de Contratación Pública", 366, n. 48.

${ }^{20}$ Tribunal de Contratación Pública, Primera cuenta pública 10. 
Procedimiento Civil. Si no lo hace, el juicio no sigue adelante y pasan más de seis meses y el demandado pide el abandono del juicio, lo declaramos, así también aceptamos el desistimiento del actor, todo ello conforme a las normas procesales del Libro I del Código de Enjuiciamiento Civil". ${ }^{21}$

c) Introducción de parámetros para aplicar medidas de restablecimiento del imperio del derecho. A falta de previsión expresa en la ley, en la primera cuenta pública se indicaron los siguientes parámetros para la pertinencia de adoptar las medidas a las que hace referencia el artículo 26 , inciso $1^{\circ}$ de la Ley de Compras: ${ }^{22}$

- si la licitación se hallaba suspendida por orden del tribunal;

— gravedad de la ilegalidad/arbitrariedad comprometida;

- si, estando la licitación adjudicada, se constata la no intervención de la conducta del adjudicatario tercero de buena fe en la comisión de la ilegalidad/arbitrariedad constatada por el tribunal;

- si el contrato licitado se encontrase ejecutado, o en fase de ejecución, y en este último caso la duración del mismo;

- la necesidad pública que deba satisfacerse; y,

-la preeminencia del interés público sobre el particular. ${ }^{23}$

d) Participación en el proceso de terceros interesados o del propio licitador adjudicatario. El título $\mathrm{V}$ de la Ley de Compras nada dice respecto de otros posibles legitimados en el procedimiento para hacer posible su actuación. Nos referimos al caso de terceros que hubiesen participado en la licitación (al que pudiese favorecer la interpretación realizada por el ente público que licita, frente a lo impugnado por otro licitador) o al mismo adjudicatario (en su caso) del contrato, comúnmente conocido en lenguaje procesal por el coadyuvante. Respecto de éstos, el TCP ha admitido su participación, siguiendo las reglas del

${ }^{21}$ Ver Álvaro Arévalo, "Rol del juez en el proceso administrativo licitatorio", 7. Discurso en el seminario "Contratación administrativa y compras públicas", celebrado el 28 de mayo de 2014 en la Facultad de Derecho de la Pontificia Universidad Católica de Chile. Disponible en http://www.tribunaldecompras.cl.

22 Tribunal de Contratación Pública, Primera cuenta pública, 8-9.

${ }^{23}$ Sobre estas causales, ver críticas en Ricardo Concha, "Crítica a la falta de declaración de nulidad y a la consiguiente configuración de la eficacia del contrato público inválido soportado en un procedimiento ilegal", Revista de Derecho de la Pontificia Universidad Católica de Valparaíso XLVI (2016), las que, en parte, compartimos. 
Código de Procedimiento Civil. ${ }^{24}$ Quizá la clave esté en el inciso $3^{\circ}$ del artículo 24 al señalar que "la acción podrá ser interpuesta por toda persona natural o jurídica, que tenga un interés actualmente comprometido en el respectivo procedimiento administrativo de contratación". Ambos tendrían un interés claramente comprometido. ${ }^{25}$

\subsection{Informes oficiales y recomendaciones de la OCDE relativos a contratación pública}

Entre los diversos informes que organismos nacionales e internacionales han confeccionado, y que hacen expresa mención al TCP como órgano jurisdiccional de resolución de controversias sobre licitaciones públicas, quisiéramos destacar los siguientes extractos de tres de ellos: ${ }^{26}$

i) El Informe sobre recomendaciones, elaborado por la Comisión de Perfeccionamiento de las Compras Públicas, prevé dos puntos relativos a la necesidad de optimizar el TCP en sus páginas 18 y 19:

Por una parte, requiriendo una modificación legal, ${ }^{27}$ propone aumentar el número de audiencias mensuales del tribunal, con motivo del

${ }^{24}$ Arévalo, "Rol del juez", 8. De hecho, más adelante critica el hecho de que la Ley de Compras no dijera nada al respecto (11).

25 En Carolina Mora, "La protección de los particulares frente a la administración pública contratante: el caso del Tribunal de Contratación Pública", en Perspectivas para la modernización del derecho de la contratación administrativa. Actas de las XI Jornadas de Derecho Administrativo, editado por Jorge Bermúdez Soto (Valparaíso: Escuela de Derecho PUCV, 2016), 231-248. Ella observa la falta de definición por parte del legislador, de lo que debe entenderse por "interés actualmente comprometido". Entiende que el interés estará presente mientras el proponente en una licitación tenga la posibilidad de adjudicarse el contrato que se licita; no considerándolo interesado si éste fuera definitivamente excluido del proceso de licitación "toda vez que pese a haber participado de él, no tiene posibilidad actual de adjudicarse el contrato". En nuestra opinión, la exclusión de un participante podría obedecer a motivos perfectamente justificables; como también podría no estar debidamente motivada la exclusión. En este último caso, entendemos que la legitimación activa no debiese decaer de forma tan simple.

${ }^{26}$ Consejo Asesor Presidencial contra los Conflictos de Interés, el Tráfico de Influencias y la Corrupción, Informe final, abril de 2015 (Santiago, 2015); Dirección de Compras y Contratación Pública, Informe de recomendaciones. Comisión de Perfeccionamiento de las Compras Públicas (Santiago, 2013); OCDE, "Recomendación del consejo en materia de contratación pública”, 2015.

${ }^{27}$ La que fue llevada a cabo mediante la Ley 20.883 de 2 de diciembre de 2015. Entre otras modificaciones a otros cuerpos legales, se aumentó el número de sesiones mensuales del tribunal, como se concreta más arriba. 
incremento sustancial de causas entre los años 2005 a 2013: "La actual carga de trabajo (...) hace insuficiente el actual número de audiencias para la adecuada resolución de los asuntos de que conoce el tribunal y para la realización de diligencias probatorias oportunas. Actualmente se toman cinco pruebas en cada audiencia, lo que pugna con la tramitación breve y sumaria del procedimiento judicial, así como con la dictación oportuna de sentencias".

Por la otra, instando a constituir una comisión experta que evaluase en profundidad medidas de perfeccionamiento al TCP, en aspectos tales como: aplicación de competencia del tribunal, agilización de procedimientos, entre otros. ${ }^{28}$

ii) En el Informe final, abril de 2015, elaborado por el Consejo Asesor Presidencial contra los Conflictos de Interés, el Tráfico de Influencias y la Corrupción (comúnmente conocido como Informe Engel), prevé, dentro de sus propuestas relativas a la prevención de la corrupción (capítulo I del Informe) un apartado C denominado: "Reforma del sistema de compras públicas, concesiones y gastos en Defensa". En cuanto a las propuestas relativas al Sistema ChileCompra, punto 9, indica literalmente: "Fortalecer al Tribunal de Contratación Pública en su estructura orgánica y perfeccionar el procedimiento judicial. Ampliar las competencias del tribunal de modo de incluir la ejecución del contrato, y otorgarle facultades para proponer modificaciones legales y reglamentarias en materia de compras públicas. Dotarlo de mayores capacidades y recursos en función de la cantidad de demandas que sean recibidas" (41-44).

Por otra parte, en el capítulo II del Informe, relativo a la regulación de conflictos de interés, apartado B, denominado "Declaraciones de patrimonio e intereses", prevé la necesidad de que ciertas autoridades cumpliesen con la obligación de declarar su patrimonio para poder constatar las posesiones del funcionario durante y después del ejercicio de su cargo, para así poder determinar si aquél pudiera eventualmente incurrir en un enriquecimiento ilícito o en otros delitos contra la probidad. Entre ellas, entienden los suscriptores del Informe Engel, debieran

${ }^{28}$ Como resultado de esta programación, se llegó a reunir dicha comisión entre 2015 y 2016, elaborando el Informe final. Mesa de trabajo para la modificación de la Ley 19.886, Dirección de Compras y Contratación Pública, que es tratado más abajo. 
incluir a "los integrantes titulares y suplentes del Tribunal de Contratación Pública y el ministro de fe, además del secretario y el relator del tribunal" (58-61). ${ }^{29}$

iii) El consejo de la OCDE sobre contratación pública, en febrero del 2015, recomienda dos puntos a destacar:

-Establecimiento de vías efectivas para la impugnación de resoluciones en materia de contratación pública, dirigidas a la corrección de defectos, impedir conductas ilícitas; además de la existencia de una fiscalización independiente y específica, y unos mecanismos adecuados de reparación.

-Coordinación entre los mecanismos de control interno y externo, mayor integración, y que dispongan de suficientes recursos, con el fin de garantizar, entre otros aspectos, la aplicación uniforme de las leyes y reglamentos, así como evitar su incumplimiento.

\subsection{Propuestas oficiales de cambios al TCP entre los años 2015 y 2017}

Cabe destacar que posibles cambios al TCP fueron objeto de análisis y debates, entre los años 2015 y 2017, en reuniones de trabajo y evaluaciones del sistema de compras públicas, organizadas e impulsadas por la propia Dirección de Compras. A continuación, primero, se indican cuáles fueron las propuestas resultantes de una mesa de trabajo que tuvo lugar desde agosto de 2015 hasta marzo de 2016, con el objeto de introducir modificaciones en la Ley de Compras, específicamente, en cuanto a su capítulo V, sobre el TCP (1.4.1). Luego, se señalan brevemente los primeros resultados del informe final del proceso de evaluación del Sistema de Compras Públicas, realizado a través de la metodología MAPS (2016-2017), que inciden sobre el TCP (1.4.2).

\subsubsection{Propuestas resultantes de la mesa de trabajo para la modificación de la Ley 19.886}

Entre agosto de 2015 y marzo de 2016, en las dependencias de la Dirección de Compras, tuvieron lugar varias reuniones de trabajo entre

${ }^{29}$ Actualmente, el sitio web del TCP prevé la pestaña "Declaración de intereses y patrimonio", en la que, cumpliendo con lo propuesto en el citado informe, refleja dichas informaciones referente a su presidente, jueces titulares, suplentes y al secretario abogado (última visita, 24 de julio de 2017). 
académicos y profesionales pertenecientes tanto a entidades fiscalizadoras como a organismos de la administración activa, con el objetivo de debatir mejoras para la modificación de la Ley 19.886. Se discutieron dos grandes puntos: la cobertura del Sistema de Compras Públicas regulado por la Ley de Compras y la institucionalidad del Sistema de Compras Públicas establecido por dicha ley.

Por medio del Portal Transparencia, tuvimos acceso al documento Informe final. Mesa de trabajo para la modificación de la Ley 19.886, de la Dirección de Compras y Contratación Pública, en adelante Informe final. ${ }^{30}$ De este documento, por razón del tema abordado en este artículo, únicamente haremos referencia a las propuestas relativas a la institucionalidad del Sistema de Compras Públicas establecido por la Ley de Compras, específicamente, a todo lo que diga relación con el TCP. ${ }^{31}$

Respecto del apartado dedicado a la institucionalidad, quisiéramos destacar la existencia de dos momentos relativos al control de las licitaciones, uno de carácter previo o ex ante, realizado por organismos diferentes al TCP, y el otro ex post, con ocasión de la intervención de éste. Veamos seguidamente ambos:

\section{i) El control ex ante de las licitaciones}

Se trata de un conjunto de medidas — modificaciones y añadidos en la Ley de Compras, u otras normas - que tienen como fin común controlar la legalidad de los procesos licitatorios, previo a que el TCP pudiera entrar a conocer del respectivo asunto. Seguidamente, de forma sucinta, enunciaremos los tres mecanismos fiscalizadores que se identificaron:

a) Reconocimiento legal del "Departamento Observatorio" de la Dirección de Compras. Actualmente, la Dirección de Compras cuenta con un departamento no reconocido legalmente, que opera como herramienta de colaboración para las entidades compradoras, consistente en

${ }^{30}$ Recibido el 11 de agosto de 2016. El informe consta de cinco partes: i) un resumen ejecutivo sobre su contenido; ii) un apartado que describe antecedentes sobre el Sistema de Compras Públicas; iii) las propuestas relativas al llamado "Foco n. 1 Cobertura del Sistema"; iv) las propuestas relativas al llamado "Foco n. ${ }^{\circ} 2$ Institucionalidad" $y$, finalmente v) un anexo que incluye el anteproyecto de modificación legal.

${ }^{31}$ El contenido global de lo debatido, de alguna forma, puede llegar a afectar indirectamente al TCP. No obstante, por razones de extensión y temática abordada, en este trabajo únicamente nos referiremos a aquellos aspectos que inciden directa y significativamente sobre la organización, competencia o procedimiento de éste. 
un sistema integrado de alertas, campañas, monitoreo permanente de los usuarios, y como mecanismo para prevenir irregularidades en procesos de compras públicas. ${ }^{32}$ Se propone darle reconocimiento expreso en la ley, y facultarlo para impartir orientaciones y recomendaciones generales, que conduzcan a difundir buenas prácticas y fortalecer la probidad en las compras públicas.

b) Introducción de mecanismos preventivos en la Ley 18.695, Orgánica Constitucional de Municipalidades. Ante el hecho observado de que los municipios son objeto de constantes reclamos en el sistema de compras públicas, ${ }^{33}$ se señalaron dos mecanismos para intentar mejorar la transparencia y probidad en el ámbito municipal:

Uno. En aquellos contratos para el suministro de bienes o prestación de servicios por montos iguales o superiores a 500 UTM, ante los cuales el alcalde requiere la aprobación de la mayoría absoluta del concejo municipal para su aprobación, se propone que el respectivo concejo no pueda rechazar la propuesta del alcalde por motivos ajenos a los contemplados en las bases; esto, en atención a que es en aquella etapa donde hoy suelen ocurrir irregularidades.

Dos. Considerando que actualmente los concejales no tienen condición de funcionarios municipales y, por lo tanto, no procede perseguir de éstos responsabilidad administrativa respecto de sus actuaciones en los procedimientos de contratación de la Ley de Compras, y que ante tales casos, la Contraloría General de la República (CGR) - de acuerdo a la normativa vigente - no tiene competencia para determinar la concurrencia de contravención grave al principio de probidad administrativa ante el Tribunal Electoral Regional respectivo, se propone establecer la responsabilidad administrativa respecto de dichos procedimientos de contratación, lo que se traduciría en la posibilidad que la Contraloría pueda ejercer sus potestades fiscalizadoras de las actuaciones de los concejales ante tales supuestos.

c) Ampliación del ámbito de control de la CGR en las licitaciones municipales por sobre las 5.000 UTM. Siendo que actualmente la Contraloría únicamente tiene un control ex post (auditorías) respecto de este tipo de licitaciones, se propone incorporar el trámite de toma de razón respecto de todos los procesos licitatorios de mayor cuantía — sobre las

\footnotetext{
32 Definición dada por el Informe final, 13.

${ }^{33}$ De acuerdo al Informe final, cercano al 50 por ciento. Ver página 13.
} 
5.000 UTM - que realizan los municipios a través del Sistema de Compras Públicas. ${ }^{34}$

ii) El control ex post de las licitaciones: las propuestas de ampliación de la competencia del TCP y corrección de sus procedimientos

La mesa de trabajo detectó dos grandes falencias derivadas de la actual regulación del tribunal:

En primer lugar, las consecuencias de su acotado ámbito competencial impiden un conocimiento más especializado de las fases posteriores al proceso licitatorio. En segundo lugar, ante el diagnóstico de que las decisiones del tribunal suelen verse desprovistas de eficacia, porque una vez adjudicada la licitación nacerían derechos adquiridos legítimamente por el adjudicatario, que empecerían al tribunal a declarar la nulidad con sus consiguientes efectos, se acordó introducir mejoras que conduzcan a mejores resultados. ${ }^{35}$

Siguiendo el orden debatido por la mesa de trabajo, en el anexo adjunto a este artículo, ofrecemos una tabla que refleja — sin perjuicio de repetir puntos ya tratados- las ambiciosas propuestas de mejora relativas a los aspectos organizativos y de funcionamiento, sobre competencia del Tribunal y el procedimiento ante éste; junto con describir previamente la situación actual de cada uno de los puntos respectivos. ${ }^{36}$

1.4.2. Propuestas que inciden sobre el TCP, reflejadas en el borrador del Informe final de evaluación del Sistema de Compras Públicas a través de la metodología MAPS ${ }^{37}$

A finales de 2016, el Gobierno de Chile, a través de ChileCompra, solicitó que el Sistema de Compras Públicas chileno se sometiera

${ }^{34}$ Ibídem, 14-15.

35 Ibídem, 15-16.

${ }^{36}$ Las sugerencias de modificación precisas a la Ley de Compras que afectan al tribunal se encuentran en el marco de las páginas 30-42, que conjugaremos con el esquema general previsto desde las páginas 15 a la 17 del Informe final. El anteproyecto de modificación legal prevé, además de modificar los actuales artículos 22 al 27 de la Ley de Compras, la propuesta de incluir nada menos que quince artículos nuevos, los cuales introducen nuevos aspectos o desplazan contenido de los anteriores: 23 bis, 24 bis, 24 ter, 25 bis, 25 ter, 25 quáter, 25 quinquies, 25 sexies, 26 bis, 26 ter, 26 quáter, 26 quáter, 26 quinquies, 26 sexies y 27 bis.

${ }^{37}$ Informe de mayo de 2017. Tuvimos acceso a él al haber participado en el levantamiento de información. 
a un proceso de auditoría comúnmente utilizado para la evaluación de este tipo de sistemas (MAPS: Methodology for Assessing Procurement Systems), con el objeto de poder detectar fortalezas y debilidades del sistema actual.

Para el levantamiento de información que sirviera de base a la confección del informe final, la Dirección de Compras realizó un llamado a los profesionales y usuarios que, de alguna manera, pudieran colaborar con sus aportaciones y opiniones acerca del Sistema.

Uno de $\operatorname{los}_{\text {pilares }}{ }^{38}$ que el mencionado instrumento evaluador sometió a consideración dice relación con el TCP. Se consideró que, si bien se valora su existencia para favorecer la rendición de cuentas, integridad y transparencia del Sistema de Compras Públicas, ${ }^{39}$ por otro lado, consideró como brecha sustantiva ${ }^{40}$ el hecho que el tribunal no sea también conocedor de la fase de ejecución de los contratos (desde la post adjudicación hasta la terminación del contrato), siéndole actualmente atribuida esa función a los tribunales ordinarios. ${ }^{41} \mathrm{Al}$ respecto, el informe señalaba: "Esta brecha debería solucionarse a través de modificaciones tanto a la Ley 19.886 como a su reglamento, tanto para ampliar las competencias del TCP como para introducir las funciones y responsabilidades de la fase de gestión de contratos". 42

Consideramos acertada la extensión del ámbito competencial del TCP hacia la fase post adjudicación, si bien, curiosamente, el borrador del informe no pareciera reflejar otras necesidades de adaptación del tribunal en cuanto a diferentes aspectos como los que aquí se tratan.

${ }^{38}$ El sistema de evaluación MAPS ha evaluado íntegramente el Sistema de Compras Públicas, por medio del análisis de cuatro pilares básicos, a saber: pilar I: marco legal, regulatorio y de políticas; pilar II: marco institucional y capacidad de gestión; pilar III: operaciones de adquisiciones públicas y prácticas de mercado; pilar IV: rendición de cuentas, integridad y transparencia del sistema de compras públicas.

39 "Borrador del informe final", 16, según los resultados de evaluación del pilar IV.

${ }^{40}$ En efecto, uno de los objetivos de esta evaluación, es la detección de "brechas sustantivas" (aquellos aspectos críticos que conviniera mejorar para fortalecer el actual sistema).

41 "Borrador del informe final", 7-9.

${ }^{42}$ Ibídem. 


\subsection{Revisión crítica de la estructura y funcionamiento del Tribunal de Contratación Pública}

Desde la entrada en funcionamiento del TCP, varios son los autores que han abordado, partiendo de sus previsiones legales o bien de la observación de su praxis, la necesidad de modificar ciertos aspectos del tribunal que dicen relación con la organización y la competencia, así como el procedimiento que se sigue ante él. Buena parte de estas críticas obedecen, según se verá, a la escueta regulación a la que se sujeta el TCP, la que sin duda cabría ampliar en el sentido que se propone en este trabajo.

En este trabajo realizamos propuestas adicionales, muy estrechamente relacionadas con las señaladas por otros autores o por las resultantes de la mesa de trabajo, que pensamos pudieran ser útiles para tratar de optimizar el funcionamiento de este tribunal. Seguidamente exponemos de forma somera, y respetando la anterior tripartición, los aspectos más criticados hasta el momento. ${ }^{43}$ Para ello, las propuestas que formulamos las ordenamos en aspectos: organizativos (sección 3); competenciales (sección 4); y de procedimiento (sección 5). Pero, antes, ofrecemos una muestra de derecho comparado sobre la materia: el caso español, cuyo tribunal es el único que se asemeja al de Chile (sección 2).

\section{EL CASO DEL TRIBUNAL DE CONTRATACIÓN ESPAÑOL}

En derecho comparado, sólo cabe revisar el caso de España, único en que encontramos la existencia de un tribunal especializado para resolver conflictos sobre contratación pública similar al chileno, aun cuando ese país (a diferencia de Chile) cuenta con tribunales contencioso-administrativos. España, con una larga tradición de contenciosoadministrativo, ${ }^{44}$ ha tendido siempre a confiar la resolución de los con-

43 Prescindimos aquí realizar una descripción detallada de las previsiones legales sobre el TCP (las que ya han sido abordadas en otros trabajos) sin perjuicio de hacer alguna relación necesaria a éstos para referirnos a las críticas. Un mayor nivel de análisis en cuanto a la descripción de lo que la ley prevé al respecto puede verse en Vergara, "Tribunal de Contratación Pública".

${ }^{44}$ Los antecedentes más significativos son del siglo XIX (leyes del 2 y 6 de abril de 1845), si bien no acabó de consolidarse y perfeccionarse hasta la promulgación de la Ley del 27 de diciembre de 1956, reguladora de la jurisdicción contencioso-administrativa. 
flictos entre la administración y particulares a los órganos que integran la jurisdicción contenciosa administrativa del poder judicial.

La independencia $-\mathrm{o}$ imparcialidad - y especialización que ofrecen en su resolución, siempre han sido una garantía para los administrados que consideran vulnerados sus intereses y derechos por parte de una administración pública.

En materia de contratación administrativa ello no suponía excepción alguna. Hasta el año 2007 cabía, por una parte, la interposición de recursos administrativos ordinarios, y por la otra, recurso contenciosoadministrativo - una vez agotada la vía administrativa, en su casopara la impugnación de actos derivados de las diferentes fases que se daban en la contratación administrativa (licitación y posterior ejecución del contrato). A partir de ese año, la promulgación de una nueva norma sobre contratos del sector público ${ }^{45}$ y de posteriores modificaciones necesarias a dicha norma, ${ }^{46}$ alteró el panorama en la resolución de conflictos sobre contratación pública, fundamentalmente partiendo del conocimiento de esta materia entre la clásica jurisdicción contenciosoadministrativa y un órgano especializado independiente (u órganos, si se consideran los que algunas comunidades autónomas han creado, al amparo de la nueva legislación; a los cuales no nos referiremos).

Seguidamente, y de forma concisa, se expondrán los aspectos más relevantes sobre el contexto regulatorio de este - no tan nuevo- escenario español, de manera tal que pueda ilustrar algunas particularidades similares con el modelo chileno:

\subsection{Antecedentes comunitarios que motivaron la creación de un órgano especializado}

Como se acaba de indicar, tradicionalmente se confió el conocimiento de este tipo de contiendas a la jurisdicción contencioso-

${ }^{45}$ Expresión ésta mucho más extensa que la de administraciones públicas, incluyendo otros entes que se mueven en la órbita de la promoción y satisfacción del interés general, sin necesidad de responder a la misma naturaleza jurídica de aquéllas.

${ }^{46}$ Nos referimos a la Ley 30/2007 del 31 de octubre de 2007, "Contratos del sector público", Reino de España. Tras la trasposición de diversas directivas europeas y de necesarias adaptaciones internas, la norma actualmente aplicable es el Real Decreto Legislativo n. ${ }^{\circ} 3 / 2011$ de 16 de noviembre de 2011, "Texto refundido de la ley de contratos del sector público" (en adelante, TRLCSP), Reino de España. 
administrativa, ${ }^{47}$ no siendo necesario - a criterio del legislador español- que a la luz de las exigencias de la Unión Europea se repartiese la resolución de conflictos entre otros órganos dentro o fuera del poder judicial. La promulgación de una nueva normativa sobre contratación pública en 2007 obedeció a la necesidad de transponer la Directiva 2004/18/CE ${ }^{48}$, para la armonización de las diferentes normas de los miembros del mercado interior sobre contratación administrativa.

La Ley 30/2007 incorporaba la creación de un nuevo recurso especial en materia de contratación, el que debía ser conocido por el mismo órgano que contrataba; no obstante debió ser rectificado por la necesidad de transponer una nueva directiva, ${ }^{49}$ para garantizar, en síntesis, que el conocimiento de dicho recurso se atribuyera, no al órgano contratante, sino a un órgano independiente, especializado, de fuera o dentro del poder judicial, que proporcionase un sistema de recursos especial, rápido y eficaz. ${ }^{50}$

Así entonces, fue que la Ley $34 / 2010^{51}$ modificó varios artículos de la 30/2007 e incorporó otros nuevos, regulando con mayor detalle no sólo el recurso especial en materia de contratación, sino también la creación de este organismo (el Tribunal Administrativo Central de Recursos Contractuales, en adelante TACRC), con la respectiva regulación del procedimiento, medidas provisionales, entre otros aspectos.

${ }^{47}$ Salvo algunos casos que se conferían a la jurisdicción civil.

${ }^{48}$ Las "directivas" son derecho comunitario, que vinculan a los Estados de la Unión Europea. Ésta es del 31 de marzo de 2004, sobre la coordinación de los procedimientos de adjudicación de los contratos públicos de obras, de suministros y de servicios.

49 2007/66/CE de 11 de diciembre de 2007, del Parlamento Europeo y del Consejo de la Unión Europea, por la que se modifican las Directivas n. ${ }^{\circ}$ 89/665/ CEE y n. ${ }^{\circ}$ 92/13/CEE del Consejo en lo que respecta a la mejora de la eficacia de los procedimientos de recursos en materia de adjudicación de contratos públicos.

50 "El modo en que se debe materializar la eficacia del recurso es a través de la atribución de la competencia para su resolución a un órgano independiente de la entidad que haya dictado el acto recurrido" señala Miguel Ángel Bernal, "Aspectos orgánicos del recurso especial en materia de contratación pública en las comunidades autónomas", Cuadernos de Derecho Local 26 (2011): 11.

${ }^{51}$ De 5 de agosto, de modificación de la Ley n. ${ }^{\circ}$ 30/2007 del 30 de octubre, de "Contrato del sector público", 31/2007 del 30 de octubre, sobre procedimientos de contratación en los sectores del agua, la energía, los transportes y los servicios postales, y de la Ley n. ${ }^{\circ}$ 29/1998 del 13 de julio, reguladora de la jurisdicción contencioso-administrativa para adaptación a la normativa comunitaria de las dos primeras. 


\section{Señala González-Varas:}

Las cada vez mayores exigencias que en lo procesal impone el derecho europeo (...) terminan provocando la creación de un órgano más adecuado, en su funcionamiento, a las exigencias de la justicia administrativa de los licitadores y del interés público, con plazos más adecuados, cortos y matizados y con un régimen de suspensión cautelar general e incluso con la previsión de medidas preventivas, que se imponen desde Europa. ${ }^{52}$

\subsection{Características del órgano resolutor en materia de licitaciones públicas}

Siguiendo las exigencias comunitarias, este órgano cumple con los siguientes requisitos:

i) Es un órgano con independencia funcional en el ejercicio de sus competencias

Si bien orgánicamente no es independiente, dado que se adscribe al Ministerio de Economía y Hacienda, la propia ley declara que su actuación se desarrollará "con plena independencia funcional en el ejercicio de sus competencias". ${ }^{53}$ Adicionalmente, contra su resolución, únicamente cabe recurso contencioso-administrativo ante la jurisdicción contencioso-administrativa, no siendo posible volver a la vía administrativa; hecho que confirmaría su independencia funcional. Lo anterior se complementa con un régimen de incompatibilidades para ejercer como integrante del tribunal e inamovilidad en el cargo. ${ }^{54}$

52 Santiago González-Varas, "La normativa europea procesal de contratación pública y el sistema actual de recursos contractuales", Revista Documentación Administrativa 288 (2010): 49. Llama la atención este autor sobre el papel protagónico que juegan los órganos cuasi jurisdiccionales, como el que existe en materia de defensa de la competencia, frente al a veces rol "puramente testimonial o reiterativo de lo resuelto por aquella otra instancia de control" (refiriéndose a la Comisión Nacional de la Competencia), donde el contencioso-administrativo judicial tendría "un papel más reducido, puramente jurídico, y que además en sede contenciosa se enjuician todos los elementos de juicio, incluidos los aspectos técnicos, con la ayuda de pruebas periciales, optando muchas veces el juzgador por una remisión a tales informes" (Ibídem, 50).

${ }^{53}$ Art. 41.1 TRLCSP.

${ }^{54}$ Comparar Juan José Pardo, "El Tribunal Administrativo Central de Recursos Contractuales", Revista Documentación Administrativa 288 (2010): 23. 
ii) Es un órgano especializado en la resolución de conflictos

La composición mínima de sus integrantes considera un presidente y dos vocales. En los tres casos se exige licenciatura en derecho, con desempeño superior a quince años, preferentemente en el ámbito del derecho administrativo, relacionado directamente con la contratación pública.

\section{iii) Prevé un régimen de justicia cautelar garantista}

Los propios licitadores podrán solicitar, previo a la interposición del recurso, la adopción de medidas provisionales. Veremos con más detalle este punto abajo.

iv) Los plazos de resolución son breves, en comparación a los de los órganos judiciales ${ }^{55}$

Ello acorde con las exigencias de la Comunidad Europea, para garantizar la tutela de los intereses involucrados en las licitaciones. ${ }^{56}$

\subsection{Particularidades destacables sobre el órgano de resolución de conflictos en materia de contratación pública}

Merece la pena destacar algunas particularidades de este órgano, que permitan ser contrastadas con falencias que presenta el modelo chileno. Prescindiremos de describir aspectos que no sean contrastables, o bien que no digan relación directa con el objeto de este trabajo:

${ }^{55}$ La anterior distribución en el conocimiento de conflictos sobre contratación pública (recursos administrativos y, con posterioridad, los órganos de la jurisdicción contencioso-administrativa) llevaba aparejada un doble inconveniente: por un lado, la continuación del procedimiento de contratación en el que se dictó la resolución cuya legalidad se discute en los órganos judiciales y, por el otro lado, el excesivo lapso de tiempo que discurre hasta la obtención del pronunciamiento judicial pretendido. Ver VV.AA., Patologías de la contratación pública (Madrid: GómezAcebo y Pombo Abogados, 2014), 32.

56 Según la última "Memoria de actividades" del Tribunal Administrativo Central de Recursos Contractuales (http://www.minhafp.gob.es/TACRC/Documentos/MEMORIA\%20TACRC\%202016.pdf), en 2016, el plazo medio de resolución de los recursos desde su presentación en el tribunal o en el órgano de contratación hasta la aprobación de la resolución correspondiente fue de 43 días naturales. En 2015, ese plazo fue de 39 días; en 2014, 36 días; en 2013, 27 días. El aumento progresivo del plazo quizá se deba a la recuperación de la actividad económica en España, lastrada desde el año 2008 por la crisis. 
i) Establecimiento de una cautela especial para evitar adjudicaciones posiblemente viciadas, en caso de que el contrato pueda ser objeto de recurso especial en materia de contratación

Con el propósito de evitar posibles adjudicaciones que no hayan respetado el procedimiento, o la correcta aplicación de criterios de adjudicación, la ley establece que el contrato con el adjudicatario no podrá formalizarse antes de que transcurran quince días desde que se remita la notificación de la adjudicación a los licitadores y candidatos (art. 156.3 de la Ley de Contratos del Sector Público). Esto permite considerar la posibilidad de que pueda haber algún licitador que se considerase perjudicado, y con derecho a la interposición de recurso.

ii) Posibilidad de poner de manifiesto defectos de tramitación no recurribles

Aquellos actos de trámite que no se consideren cualificados a efectos impugnatorios, con el objetivo de enderezar la correcta tramitación del procedimiento, podrán ser puestos de manifiesto por los licitadores, dándoles así un papel activo. Ello sin perjuicio de que dichas irregularidades puedan ser alegadas por éstos al recurrir el acto de adjudicación.

iii) Previsión de un régimen previo de nulidad especial

Siguiendo el artículo 37 y siguientes de la ley, cierto tipo de contratos se consideran nulos ante determinadas circunstancias. La cuestión de nulidad deberá plantearse ante el TACRC por cualquier persona física o jurídica cuyos derechos o intereses legítimos se hayan visto perjudicados o puedan resultar afectados por estos supuestos de nulidad especial. Los supuestos que aquí interesan son los siguientes:

- Cuando no se hubiese respetado el plazo de espera de quince días hábiles del artículo 156.3 de la Ley de Contratos (arriba referido) previo a la formalización del acuerdo, siempre que el licitador se hubiese visto privado de la posibilidad de interponer recurso especial, en presencia de alguna infracción de los preceptos que regulan el procedimiento de adjudicación que le hubiera impedido interponerlo.

- Cuando, a pesar de haber interpuesto el recurso especial, se lleve a cabo la formalización, sin tener en cuenta la suspensión automática del acto de adjudicación (por la interposición de éste, ex. art. 45 de la 
Ley de Contratos), y sin esperar a que el tribunal hubiese dictado resolución sobre el mantenimiento o no de la suspensión.

El efecto de dicha declaración de nulidad ${ }^{57}$ comporta, cuando sea firme, la liquidación del contrato, restitución recíproca de las cosas que las partes hubiesen recibido en virtud del mismo, y la indemnización a la parte perjudicada por esta declaración de nulidad.

iv) Contemplación de un régimen de medidas provisionales con detalle procedimental

Los legitimados para la interposición de recurso, previo a su presentación, pueden solicitar la adopción de medidas provisionales, entre ellas la suspensión del procedimiento. Se dará audiencia al órgano licitante para que pueda presentar las alegaciones oportunas referidas a la adopción de medidas solicitadas o a las propuestas por el tribunal; siendo que el silencio del órgano licitante supondrá la continuación del procedimiento ante el tribunal.

v) Necesidad de anuncio previo a la interposición de recurso especial

Con el objetivo de alertar al ente licitante, se impone la obligación de anunciar la interposición a éste, señalando el acto del procedimiento que se impugna. Paralelo a ello, cabrá interponer el recurso dentro de los plazos que la norma señala en cada caso.

vi) Particularidades de la suspensión del procedimiento

Merece la pena repasar algunas medidas notables de ese modelo, que pudieran dar respuesta a los problemas asociados actualmente a la medida cautelar de suspensión ejercida por el TCP (que más adelante señalaremos):

a) En primer lugar, si el acto recurrido es la adjudicación del contrato, una vez interpuesto el recurso, se produce la suspensión automática de la tramitación del expediente de contratación. En este caso, el tribunal dispone de cinco días para pronunciarse sobre si levanta dicha suspensión establecida ex lege o bien si la mantiene. Por otra parte, si el acto impugnado es diferente al de la adjudicación, el reclamante tiene la posibilidad de solicitar al tribunal la suspensión, el cual, mediante la ponderación de los intereses en juego, resolverá lo que proceda. Ambas

57 Sin perjuicio de que el tribunal aprecie que la declaración de nulidad comporte consecuencias desproporcionadas muy justificadas, estableciendo la ley supuestos que no se consideran razones imperiosas de interés general, para evitar demasiada discrecionalidad en este campo. 
medidas van encaminadas a corregir infracciones de procedimiento o impedir que se causen perjuicios a los intereses afectados.

b) La segunda medida contemplada es que, cuando de la adopción de las medidas provisionales pudieran derivarse perjuicios de cualquier naturaleza, la resolución podrá imponer la constitución de una contra cautela al reclamante, que fuera suficiente para responder de ellos, sin que las medidas provisionales produzcan efectos hasta la efectiva constitución de la oportuna garantía.

c) En la tercera medida, con motivo de la dictación de la resolución final, el tribunal deberá acordar el levantamiento de la suspensión del acto de adjudicación si en el momento de dictarla continuase suspendido, así como de las restantes medidas cautelares que se hubiesen acordado y la devolución de las garantías cuya constitución se hubiera exigido para la efectividad de las mismas, si procediera.

vii) Necesidad que el tribunal garantice la confidencialidad y el derecho a la protección de los secretos comerciales en relación con la información que contenga el expediente de contratación

El artículo 46.5 de la Ley de Contratos prevé esta garantía, sin perjuicio que el propio tribunal pueda tomar en consideración dicha información a efectos de resolver.

viii) Posibilidad que el tribunal fije la indemnización por daños $y$ perjuicios ocasionados por infracción legal que hubiese dado al recurso

En el caso español, es el propio tribunal quien fija la indemnización, con arreglo a los criterios contenidos en la legislación sobre régimen jurídico del sector público. ${ }^{58} \mathrm{El}$ artículo 48.2 de la Ley de Contratos establece que, cuando menos, la indemnización deberá resarcir los gastos ocasionados en la preparación de la oferta o participación en el procedimiento de contratación. Esta resolución, al devenir firme, será directamente ejecutiva (art. 49.2 de la Ley de Contratos), sin necesidad entonces que sea calculada ni ejecutada por órgano judicial alguno.

Obviamente, lo deseable no sería - desde el punto de vista del licitador perjudicado que no haya podido ejecutar el contrato, por lo

${ }^{58}$ Art. 34 de la Ley n. ${ }^{\circ}$ 40/2015 de 2 de octubre de 2015, "Régimen jurídico del sector público", Reino de España. 
avanzado de su estado, o por cualquier eventualidad que imposibilitara su readjudicación - dar por satisfechos los intereses del perjudicado, mediante el cobro de una indemnización. Como señala acertadamente Pardo:

Si la resolución es adoptada tardíamente, el restablecimiento pleno de la legalidad no se puede alcanzar nunca a través de ella, pues la adjudicación y (...) la ejecución del contrato, se habrán producido con anterioridad a que se dicte aquélla (...). Es cierto que siempre cabe la posibilidad de acordar la correspondiente compensación económica, pero ésta no es sino una solución alternativa y, por supuesto, no constituye la plena satisfacción de lo pretendido. (...) baste con señalar como una motivación habitual de la contratación, la de poder adquirir datos objetivos de solvencia que le permitan optar, en licitaciones futuras, a la adjudicación de determinados contratos (...) este objetivo queda truncado si no se logra la adjudicación del contrato como consecuencia de una infracción legal cometida en el procedimiento de adjudicación por el órgano de contratación. ${ }^{59}$

\section{PROPUESTAS RELATIVAS A LA ORGANIZACIÓN DEL TCP}

Para contextualizar este primer grupo de aspectos críticos sobre la organización y funciones, y las propuestas que formulamos, conviene señalar de base que este tribunal, con asiento en Santiago, está compuesto por tres abogados integrantes especializados titulares y tres suplentes; un secretario, tres abogados relatores más el personal administrativo; que sesiona de lunes a viernes y que depende presupuestaria y materialmente de la Dirección de Compras y Contratación Pública. Para la presentación de la demanda en regiones, dado que sólo existe un tribunal, se prevé la necesidad de acudir a la intendencia regional o gobernación regional respectiva. ${ }^{60}$ Teniendo presente lo anterior, los aspectos críticos a nuestro juicio son los que siguen:

${ }^{59}$ Pardo, "El Tribunal Administrativo Central", 25-26.

${ }^{60}$ Esta regulación se contiene en los artículos 22 y 23 de la Ley de Compras y, con más detalle, en el auto acordado de la Corte Suprema de 2011. 


\subsection{EI TCP requiere mayor independencia organizativa y presupuestaria}

Pareciera necesaria la dotación no sólo de una partida presupuestaria totalmente independiente para el $\mathrm{TCP},{ }^{61}$ desvinculada de la Dirección de Compras (dado que ésta también puede llegar a ser justiciable ante el tribunal), ${ }^{62}$ que pase a ser autogestionada; sino además, unos recursos humanos, técnicos y logísticos -incluyendo la sede donde desarrolle su actividad - independientes de aquélla; todo enfocado a garantizar su autonomía e imparcialidad. ${ }^{63}$ Para asegurar esta independencia, como se ha apuntado ${ }^{64}$ el TCP podría subordinarse exclusivamente al Ministerio de Hacienda o Economía, lo que ya acontece con otros tribunales especializados, como es el caso del Tribunal de Defensa de la Libre Competencia (TDLC) o el Tribunal de Propiedad Industrial; si bien pensamos que dicha autonomía pudiese estar también sujeta a posibles tensiones.

Por otra parte, mirando el modelo español, pudiera también presentar problemas hacer depender al tribunal del poder judicial, si, a resultas de ello, la independencia que garantiza la vía judicial se viese desplazada por la demora en resolver, o adoptar medidas suspensivas (por sobreacumulación de causas). Por lo tanto, no basta con que el órgano goce de independencia en la resolución de conflictos, sin que ello venga

${ }^{61}$ Siguiendo a Felipe Olmos, "Aspectos orgánicos y competencia del Tribunal de Contratación Pública", en Lara y Bocksang, Procedimiento administrativo y contratación pública, 457. La dependencia presupuestaria ha disminuido en los últimos años, al haber conseguido "una glosa presupuestaria independiente dentro del presupuesto de la Dirección", si bien critica más abajo que "es inadecuado que el legislador haya entregado [a la] Dirección de Compras y Contratación Pública la función de proveer materialmente al tribunal, si se considera que la Dirección como organismo público integrante de la Administración del Estado es justiciable ante el Tribunal de Contratación Pública".

${ }^{62}$ Véase, por ejemplo, "Diálisis Renca Limitada con Dirección de Compras y Contratación Pública”, 2008.

${ }^{63}$ Ello es algo de lo que se ha hecho eco en algunos trabajos: Lara y GarcíaHuidobro, "Aspectos críticos de la solución", 415; Escanilla, "El Tribunal de Contratación”, 123; Vásquez y Koch, Institucionalidad, procedimiento y jurisprudencia, 42. En el primer trabajo citado, además, indica que esta independencia supone un agravio comparativo con respecto a otros tribunales especiales, como el caso del Tribunal de Propiedad Industrial o el de Defensa para la Libre Competencia, en los cuales sus propias leyes respectivas se encargan de resaltar este carácter independiente del que están provistos.

${ }^{64}$ Lara y García-Huidobro, “Aspectos críticos de la solución”, 418. 
acompañado de la necesidad de resolver en plazos breves y mediante procedimientos acotados. ${ }^{65}$

\subsection{Integración interdisciplinaria}

Otro punto relevante se refiere a que, en aras a un análisis más exhaustivo, técnico y preciso, pueda preverse la incorporación de especialistas de otras disciplinas - economistas en especial - que tuviesen como objetivo analizar aspectos más cercanos a su campo, y de paso dotar al criterio del TCP de un mayor acierto en la resolución de conflictos. ${ }^{66}$ Igualmente es oportuno que los jueces ante cuestiones que escapasen en parte de su ámbito de conocimientos puedan, por medio de las medidas para mejor resolver (contempladas en inciso $6^{\circ}$ del artículo 25 de la Ley de Compras Públicas), solicitar un informe al especialista que mejor corresponda con ocasión del reclamo presentado, para arrojar mayor claridad sobre dichos aspectos. ${ }^{67}$

\subsection{Mayor participación del TCP en la proposición de modificaciones legales sobre contratación pública}

Qué mejor opción que contar con un testigo directo de los conflictos y problemas de esta área, para optimizar la regulación actual. ${ }^{68}$ Por ello, sería conveniente ofrecerle a este órgano una vía adecuada para pronunciarse sobre propuestas legislativas que ayuden a la mejora y eficiencia tanto del mismo como a la satisfacción de los derechos en juego. Así lo manifestó indirectamente el tribunal, sin el respaldo de competencia existente en este sentido, en su primera cuenta pública, a

${ }^{65}$ Siguiendo a Joaquín Tornos, "Los tribunales independientes para la resolución de los recursos administrativos en materia de contratos del sector público", en Derecho administrativo y regulación económica. Liber Amicorum Gaspar Ariño Ortiz, coordinado por Juan Miguel de la Cuétara Martínez, José Luis Martínez López-Muñiz y Francisco J. Villar Rojas (Madrid: La Ley, 2011), 810.

${ }^{66}$ Así Lara y García-Huidobro, “Aspectos críticos de la solución”, 420 y 421.

${ }^{67}$ Como sucedió en la causa "Ingeniería y Construcciones del Pacífico Limitada con Dirección de Aeronáutica Civil”, 2009, donde se solicitó como medida para mejor resolver la realización de un peritaje conjunto que comprende materias relativas a los procesos licitatorios.

${ }^{68}$ Aspecto también sugerido expresamente por su actual presidente. Arévalo, “Rol del juez", 12. 
través de ciertas proposiciones de modificaciones normativas. ${ }^{69}$ Otros autores van más allá al proponer que pueda el TCP ostentar una competencia de proponer cambios y modificaciones legales a la normativa rectora en materia de licitaciones, contrataciones y compras públicas así como la posibilidad de solicitar la modificación de la normativa legal o reglamentaria que sea contraria a lo preceptuado por la Ley $19.886,{ }^{70}$ en comparación con el TDLC, que sí tiene esta facultad.

\subsection{Mejoramiento del auxilio en regiones}

Al ser necesaria la presentación de la demanda ante el mismo TCP, el artículo 24 inciso $4^{\circ}$ de la Ley de Compras prevé la posibilidad de su presentación ante las intendencias regionales o gobernaciones provinciales respectivas, en caso que el proveedor tuviera su domicilio fuera de la capital. Ello se complementa con el artículo 11B del auto acordado de la Corte Suprema, el que, además, prevé la posibilidad de realizarse exhortos ante el juez de letras en lo civil que corresponda, para la práctica de trámites, diligencias o actuaciones probatorias que por orden del TCP deban llevarse a cabo fuera del lugar de su asiento, todo lo cual se materializa por escrito, electrónicamente o por fax, remitiéndoles a éstos los antecedentes necesarios para cumplir tal cometido. No obstante, ello sólo contribuye a morigerar el centralismo de la tramitación de esta jurisdicción, advirtiéndose la necesidad de regular un procedimiento ad hoc, "para el debido resguardo de los derechos fundamentales de las personas como para la constitucionalidad sustantiva de medidas de organización y atribuciones que hagan realidad el principio de inmediación del TCP en el marco de un debido proceso"71.

Respecto del auxilio judicial de regiones, cabe observar en especial el tema del envío de la demanda por la intendencia o gobernación provincial. Consideramos muy conveniente la propuesta de la mesa de trabajo relativa a establecer, con carácter general, que la tramitación del procedimiento se lleve a cabo electrónicamente (véase anexo final). Sin duda ello será una contribución al fortalecimiento de la naturaleza breve y sumaria del procedimiento.

\footnotetext{
${ }^{69}$ Tribunal de Contratación Pública, Primera cuenta pública, 11-13.

${ }^{70}$ Lara y García-Huidobro, “Aspectos críticos de la solución”, 429-430.

${ }^{71}$ Escanilla, "El Tribunal de Contratación”, 122.
} 
Sin perjuicio de ello, bajo la actual regulación, señala la ley que en los casos en que el demandante tenga su domicilio fuera de la región donde el tribunal tiene su asiento, podrá presentarse la demanda por medio de las intendencias regionales o las gobernaciones provinciales respectivas, y que éstas deberán remitirla al tribunal "el mismo día, o a más tardar el día hábil siguiente, contado desde su recepción”. No obstante, ¿qué consecuencias comportaría el hecho que el gobernador o el intendente, en sus respectivos casos, no remitieran a tiempo la demanda que les haya sido entregada para su remisión al TCP?

La ley en este sentido no prevé ningún tipo de consecuencias. ¿Se generarán responsabilidades? ¿Podría eventualmente subsanarse la falta de remisión a tiempo? Si esta demanda no se presentase dentro del plazo por parte de estos terceros, sería imaginable, en principio, una mayor flexibilidad del TCP en declarar la admisibilidad —al menos en cuanto su presentación - de la demanda, siempre y cuando quedase demostrada la diligencia de quien la interpuso previamente.

Ahora bien, siendo que la presentación de la demanda ocurre previamente a la posibilidad que el tribunal decrete la suspensión del procedimiento, a falta de un conocimiento por parte del órgano licitador de que ésta se interpuso, la licitación sigue su curso. Si los responsables de la remisión de la demanda desde regiones, no la entregasen a tiempo, pudiera ocurrir que entre tanto, por ejemplo, se hubiera perfeccionado el contrato, con las consecuencias que ello comporta.

Visto lo anterior, cabe estudiar una solución institucional al interior del poder judicial y que sean, por ejemplo, los tribunales los receptores de estas demandas. Ello sería coherente con la posición institucional del TCP.

\subsection{Revisión de los días y horas de funcionamiento}

Es necesaria la revisión, en la práctica, de los días y horas de funcionamiento del tribunal. En efecto, si bien de acuerdo al auto acordado de la CS de 2011, regulador de su funcionamiento, se indica que funciona de lunes a viernes (horario éste que es propio de un órgano administrativo, pero no de un tribunal, que funciona de lunes a sábado); ello se contradice con lo previsto en el artículo 27 de la Ley de Compras en relación al cómputo de plazos del procedimiento ante aquél: de lunes a 
sábado (por aplicación supletoria del Código de Procedimiento Civil, en silencio de indicación específica por la Ley de Compras). ${ }^{72}$

\subsection{Expedientes más allá del transcurso de los cinco años de duración de los cargos}

El artículo 22, inciso $7^{\circ}$ de la Ley de Compras dispone - aun considerando las propuestas de los autores y la mesa de trabajo- que, sin perjuicio de una posible reelección, los integrantes del tribunal permanecerán en el ejercicio de sus cargos por un plazo de cinco años. Si al expirar su cargo, éstos hubiesen conocido de asuntos los cuales, estuvieran pendientes de sentencia, ¿quién deberá finalizar el trabajo empezado?, ¿el nuevo titular?

Pensamos que es necesario aclarar, siquiera a través de una modificación del auto acordado de la Corte Suprema, qué pasa en estos casos. Por ejemplo, prever expresamente un plazo de transición entre la salida del antiguo miembro integrante y la entrada del nuevo. Ello, por coherencia en la respuesta a los conflictos en curso, al menos aquellos cuyo estado de resolución estuviera avanzado.

\subsection{Adaptación del auto acordado de la Corte Suprema a las últimas modificaciones al título $\mathrm{V}$ de la Ley de Compras}

Sin perjuicio de que en su día se adapte el citado auto a las modificaciones legales que procedan, a raíz del trabajo que se llevó a cabo por la mesa de trabajo y por aportes de autores como los citados, observamos que todavía no se ha procedido a la modificación de dicho auto conforme las modificaciones realizadas en la Ley de Compras, artículo 22, generando ello evidentes contradicciones.

En efecto, dichas modificaciones tuvieron por objeto, entre otras medidas, aumentar el número de audiencias del tribunal, de la manera descrita en el punto III.1a) del trabajo, siendo que el auto acordado sigue manteniendo en su artículo 7, que las audiencias se celebrarán los días martes y jueves. Aunque debiera entenderse implícitamente

72 Véase la argumentación jurídica de este aserto en Vergara, "Tribunal de Contratación Pública”, 358 y 368-369. Si el término de presentación de demanda fuera en día sábado, ésta se hará efectiva en el domicilio de la secretaría del tribunal (informada en su sitio web: www.tribunaldecontratacionpublica.cl). 
modificado por la Ley 20.883, consideramos adecuado, por razones de seguridad jurídica y coherencia normativa, que se modificase dicha disposición de carácter reglamentario.

\subsection{Mejora del sitio web del TCP}

Si bien no se trata de una propuesta que incida sobre la modificación de la normativa aplicable, estimamos que fuera necesario actualizar su sitio web, para un análisis más actualizado y preciso del funcionamiento del tribunal (el cual arroja informaciones y estadísticas muy interesantes, pero que lamentablemente su actualización pareció dejarse de producir hace un tiempo). ${ }^{73}$

También debiera mejorar el orden en el que se dispone la información: varias de sus pestañas se limitan a reproducir lo que la ley indica al respecto; quizá pudiera aglutinarse toda la información en un único apartado, dejando la información estadística, eventos e información sobre causas y sentencias en pestañas independientes. En relación a estas últimas, se echa en falta que el buscador pudiera contener otros campos de búsqueda además del número de rol (por ejemplo, por palabras, partes, objeto de la impugnación, entre otros posibles). Sin duda ello facilitaría la búsqueda de jurisprudencia con propósitos académicos o profesionales.

\section{PROPUESTAS RELATIVAS A LA COMPETENCIA DEL TCP}

La competencia del tribunal es llamativamente acotada en varios planos, y las críticas cabe dirigirlas hacia tres aspectos competenciales: i) procedimental (en referencia a las fases procedimentales de la licitación no atribuibles al conocimiento del tribunal); ii) objetiva (con razón a aquellos procedimientos diferentes de la licitación pública y privada, que no pueden ser objeto de examen); y, por último, iii) material (relativa a cuestiones que se suscitan a lo largo del procedimiento licitatorio y que pudieren tener reflejo dentro del procedimiento contencioso-administrativo del TCP).

73 Concretamente, desde principios del 2014, observando que varios de los últimos datos son hasta el 31 de diciembre de 2013. Lo mismo acontece con el apartado relativo a las sentencias ejecutoriadas, que dejaron de ingresarse desde 2013. 


\subsection{Competencia procedimental limitada}

La competencia del tribunal (art. 24 de la Ley de Compras) se extiende básicamente a los trámites procedimentales que se den entre la fase de aprobación de las bases de la respectiva licitación y su adjudicación; no así a los actos posteriores (desde la celebración a la terminación del contrato). ${ }^{74}$ De ahí que parece curiosa la denominación del tribunal ("de contratación"), dado que su conocimiento competencial únicamente alcanza sólo a la licitación y a ninguna de las fases del contrato; en estas condiciones, debiese haberse denominado "Tribunal de las Licitaciones", o algo así. ${ }^{75}$

Los actos posteriores típicos de la contratación pública que quedan fuera del ámbito de conocimiento del TCP son:

i) La celebración y el perfeccionamiento del contrato

Observa el TCP en su primera cuenta pública el hecho de que el legislador no hubiese recogido la posibilidad de que el órgano pudiese entrar a conocer aspectos como la celebración y perfeccionamiento del contrato, tan inmediatos de la adjudicación de éste, en los cuales existe el riesgo potencial que surjan problemas. ${ }^{76}$

ii) La ejecución del contrato

La limitada competencia del TCP en lo que a las fases del procedimiento se refiere es criticable tomando en consideración el trabajo que

${ }^{74}$ Se distinguiría una regla general de competencia (contra actos y omisiones ilegales o arbitrarias, acaecidos en los procedimientos administrativos de contratación con los organismos públicos regidos por la Ley de Compras, que hayan sido impugnados mediante la acción que ella prevé en el art. 24, y dos especiales: i) actos que menciona el art. 3e) de la Ley de Compras (contratos de obra pública y otros de vivienda y urbanización) y ii) por el art. 66 de la Ley 18.695, “Orgánica constitucional de municipalidades", se extiende la competencia del TCP a la contratación y concesiones de servicio público de las municipalidades. Ver Vergara, "Tribunal de Contratación Pública", 359-360.

75 En este sentido también lo destacan: Lara y García-Huidobro, "Aspectos críticos de la solución", 410; Escanilla, "El Tribunal de Contratación”, 112; Vásquez y Koch, Institucionalidad, procedimiento y jurisprudencia, 88-89.

${ }^{76}$ Tribunal de Contratación Pública, Primera cuenta pública, 12. Al respecto indicaron: "Después de la adjudicación y antes de la suscripción del contrato, pueden ocurrir y de hecho es así, una serie de situaciones, tales como la no emisión de la orden de compra por la entidad licitante, la readjudicación a otro oferente por diversos motivos, la invalidación de la resolución adjudicatoria seguida de una nueva convocatoria, la negativa a suscribir el contrato por el cambio de las condiciones establecidas en las bases (...)". 
involucra la creación de un nuevo órgano jurisdiccional especializado, no sólo en cuanto a decisión legislativa, sino que también en materia de gestión, implementación e inversión.

Sobre este punto, se han señalado dos consecuencias derivadas de lo anterior: La primera es que por causa de la atribución del conocimiento de la fase de ejecución del contrato a la justicia ordinaria (para resolver el respectivo conflicto entre un ente público y el contratista), pudiera existir el riesgo de una probable aplicación llana del derecho privado $^{77}$, pese a la existencia, generalmente, de normas de derecho público aplicables. La segunda es la carga de dividir el conocimiento de las controversias entre el TCP (la deseada, por especialización) y la justicia ordinaria para todo lo demás (con un conocimiento más limitado). ${ }^{78}$

iii) La terminación del contrato

La terminación del contrato, por extensión, también quedó fuera. En efecto, puede que un determinado contrato termine por las causas naturales de finalización que se atienen a la correcta ejecución de lo contratado, con perfecto pago de los montos económicos correspondientes al contratista. No obstante ello, también es posible que dicho contrato finalice por incumplimiento contractual de alguna de las partes; o bien, que pueda haber sido ejecutado correctamente por el contratista pero que, no obstante, quede pendiente restituirle económicamente en orden a respetar el equilibrio económico del contrato, fruto de desembolsos o trabajos no reintegrados por el órgano contratante, en cuyo caso, generará ello una contienda si no se llega a un acuerdo. ${ }^{79}$

En definitiva, siendo el TCP un órgano con conocimientos específicos en el campo, la legislación podría haber ido más allá en la extensión de su ámbito de conocimiento, tomando en cuenta el efecto que produce relegar el conocimiento de los actos posteriores a órganos judiciales usualmente sin especialización en contratación administrativa. En derecho comparado, por ejemplo, como en el caso español, si bien hay órganos símiles que conocen de la misma materia, cuyo ámbito com-

${ }^{77}$ Lara y García-Huidobro, “Aspectos críticos de la solución”, 423.

${ }^{78}$ Escanilla, "El Tribunal de Contratación”, 136.

79 Inclusive cabría añadir los casos de terminación anticipada ordenada unilateralmente por la administración. Ver José Luis Lara y Luis Eugenio GarcíaHuidobro, "Aspectos críticos y desafíos de la contratación administrativa bajo la Ley 19.886”, en Bermúdez Soto, Perspectivas para la modernización, 142, n. 35. 
petencial también está restringido hasta la adjudicación del contrato, no obstante, para los actos relativos a la ejecución y terminación del contrato administrativo, conocen de ellos los jueces de la jurisdicción contencioso-administrativa y, por lo tanto, entes especializados, con las ventajas que ello supone. ${ }^{80}$

\subsection{Competencia objetiva limitada sólo a licitaciones públicas y privadas}

Las diferentes modalidades de contratación que comprende la Ley de Compras son, por una parte, los procedimientos (stricto senso) de licitación pública, licitación privada y contratación directa; y, por otra, los convenios marco. ${ }^{81}$ En el caso del trato o contratación directa y del convenio marco, dado que no hay licitación, la ley pareciera no comprenderlos dentro del ámbito objetivo de impugnación del artículo 24 de la Ley de Compras.

¿Acaso no resultaría necesario que ante una adjudicación contractual por medio de trato directo se verifique el interés público comprometido y la salvaguardia, en su caso, del principio de libre concurrencia? Llamativamente, ahondando en esta necesidad de transparencia, el TCP en su primera cuenta pública indicó como palabras finales que su objetivo va encaminado a velar por un sistema de compras públicas transparente y confiable. ${ }^{82}$

${ }^{80}$ Artículos 40 y 21.1 del Real Decreto Legislativo n. ${ }^{\circ} 3 / 2011$, por el cual se aprueba el "Texto refundido de la ley de contratos del sector público".

${ }^{81}$ Los tres primeros quedan recogidos principalmente en el art. 5 y el art. 7, apartados a, b y c - respectivamente- Respecto a los convenios marco, la ley se refiere por primera vez a ellos en varios apartados del art. 30 de la Ley de Compras. Todo ello sin perjuicio de que los artículos de esta ley y de su reglamento sean concordantes. Respecto del trato directo, pese a recogerse en el mismo grupo de artículos que las dos primeras modalidades, el TCP ha indicado, tanto en su jurisprudencia como institucionalmente, que no es competente para conocer de éstos (véase, por ejemplo "Grupo Bios con Servicio de Salud Metropolitano Sur Oriente”, 2009, y Tribunal de Contratación Pública, Primera cuenta pública, 6). Lo mismo pasa con los convenios marco (ver "Ingeniería y Construcción Ricardo Rodríguez y Cía. con Dirección de Compras y Contratación Pública”, 2011).

${ }^{82}$ Específicamente: "Hacer que el sistema de compras públicas sea cada día más transparente y confiable y asegure tanto a oferentes, como a las entidades licitantes y a la sociedad entera, que los bienes y servicios necesarios para la sa- 
En relación a los convenios marco, en el último informe publicado por la OCDE para Chile sobre la materia, ésta recomienda que los países adherentes fomenten una participación transparente y efectiva de las partes interesadas, brindando oportunidades "para la participación directa de las partes interesadas externas en el sistema de contratación pública, con el objetivo de potenciar la transparencia y la integridad a la vez que asegura un nivel adecuado de control, sin perjuicio del respeto constante de la confidencialidad, la igualdad de trato y demás obligaciones legales del procedimiento de contratación pública". 83

\subsection{Limitaciones de la competencia material}

En este apartado, interesa señalar tres aspectos relativos a la competencia material, los cuales no son conocidos tampoco por el TCP: i) sobre la indemnización que pudiera corresponderle al licitador no ganador, a cuyo favor el TCP hubiere declarado la ilegalidad y arbitrariedad de la adjudicación; ii) sobre el monto indemnizatorio; y iii) el conocimiento de penalizaciones y multas a las que hubiere lugar dentro del procedimiento licitatorio o bien durante la ejecución del contrato.

\section{i) Sobre el pronunciamiento indemnizatorio}

En efecto, según el tenor literal de la Ley de Compras (artículo 26, inciso $2^{\circ}$ ), el TCP únicamente está facultado para pronunciarse sobre la legalidad o arbitrariedad del acto y omisión impugnados, y a continuación dispone: "ordenar, en su caso, las medidas que sean necesarias para restablecer el imperio del derecho". Dentro de estas medidas, se encuentra, por ejemplo, declarar el derecho del licitador

tisfacción de los intereses generales de los ciudadanos encuentran en este mercado virtual la forma más justa, ecuánime y conveniente para su satisfacción y que existen además, los mecanismos adecuados para restablecer el imperio del derecho, cuando la satisfacción de estos legítimos intereses generales y particulares en juego, por cualquier razón o motivo, son perjudicados por actos ilegítimos, ya sea que provengan de las autoridades, como de los propios particulares que concurren a este mercado". Tribunal de Contratación Pública, Primera cuenta pública, 13.

${ }^{83}$ OCDE, Contratación pública en Chile. Opciones de política para convenios marco eficientes e inclusivos (París: Éditions OCDE, 2017), 18. Sobre tal temática de los convenios marco, véase: Jenny Nicólas Turrys, "Contratación administrativa a través de convenios marco: naturaleza jurídica y aplicación práctica", Revista de Derecho Administrativo Económico 20 (2015): 43-80. 
demandante perjudicado por una adjudicación no ajustada a derecho, en caso que el contrato estuviere en fase de ejecución o ya finalizado, al cobro de una indemnización. ${ }^{84}$

Si bien el TCP abre la posibilidad de reclamar — ante la justicia ordinaria - una indemnización por daños y perjuicios, ello ocasiona doble perjuicio al demandante por cuanto supone un sobrecosto y una carga adicional impuesta al perjudicado, quien deberá realizar mayores desembolsos económicos e interponer acciones adicionales. Además, el tribunal que en su día conozca del monto indemnizatorio reclamado no contará seguramente con los conocimientos especializados oportunos para brindar una solución adecuada a la situación, al ser órganos de conocimiento lato, ${ }^{85}$ a lo que cabría añadir la posible saturación de la justicia ordinaria en el conocimiento de causas.

Como solución a este problema, de conformidad al tenor literal de la Ley de Compras, si el TCP está facultado para tomar las medidas que sean necesarias para restablecer el imperio del derecho, en una interpretación extensiva bien podría conocer de la acción resarcitoria; ${ }^{86}$ no se aprecian obstáculos para ello. De hecho apela a la lógica, por evidentes razones de especialidad, economía procedimental y equilibrio en la

${ }^{84}$ Entre muchas otras sentencias, "Inducien Instruments con Dirección General de Aguas", 2014, o "Laboratorio Chile S.A. con Central de Abastecimiento del Sistema Nacional de Servicios de Salud”, 2009.

${ }^{85}$ En Lara y García-Huidobro, "Aspectos críticos y desafíos", 143-146, señalan que no hay una acción efectiva que permita tutelar los derechos de los colaboradores privados frente a posibles ilegalidades en el obrar administrativo dentro de una relación contractual. Indican, asimismo, que la Contraloría General de la República (CGR), si bien es un órgano con conocimientos especializados en derecho administrativo, no constituye una solución al problema apuntado, toda vez que según su ley reguladora, ésta debe eximirse de entrar a conocer asuntos de carácter litigioso, o bien sometidos al conocimiento de los tribunales de justicia. Al respecto citan diversos dictámenes donde el órgano contralor entendió que no debía inmiscuirse ante situaciones concretas (como los casos de exceptio non adimpleti contractus, errores de interpretación contractual por parte de organismos públicos, entre otros).

${ }^{86}$ Argumento que también comparte Escanilla, "El Tribunal de Contratación", 136-137. Propone otra solución Lara y García-Huidobro, "Aspectos críticos de la solución", 426-427, donde entienden que la acción de indemnización debería sustanciarse ante los tribunales ordinarios, si bien por medio de un procedimiento expedito y sumario, sin necesidad de acreditar la existencia de daños y perjuicio. Parecido es el razonamiento que sostiene el propio TCP en su primera cuenta pública: ver Tribunal de Contratación Pública, Primera cuenta pública, 12. 
satisfacción de los intereses privados en juego. No obstante, siguiendo estrictamente las reglas del título V de la Ley de Compras, el TCP no tiene reconocida expresamente la facultad de conocer y juzgar procedimientos en que las partes intenten perseguir la responsabilidad patrimonial de la administración mediante acciones que intenten la indemnización de perjuicio por actos que causen un daño resarcible dentro del procedimiento de compras públicas.

ii) Determinación de la cuantía correspondiente al monto indemnizatorio

Consideramos suficientes todas las propuestas formuladas hasta ahora para expandir el ámbito de conocimiento del tribunal hacia procedimientos, fases o aspectos adicionales a los que actualmente se extiende. La especialización de sus jueces integrantes en el conocimiento de la contratación administrativa es un valor añadido para la resolución de conflictos de esta naturaleza. Con todo, quisiéramos exponer la siguiente propuesta adicional a las comentadas por autores o por la mesa de trabajo.

Teniendo en cuenta esta especialización, estimaríamos conveniente que el propio TCP fuera quien, por medio de un incidente de ejecución de sentencia, y tras estudiar el monto indemnizatorio propuesto por el licitador no adjudicatario que hubiera interpuesto la demanda, en los casos en que fuera imposible retrotraer el procedimiento, se pronunciase respecto de la cuantía exacta que debiera obtener como compensación el demandante.

Cuestión posterior sería, una vez determinada la cuantía, hacerla efectiva por medio del correspondiente tribunal civil ordinario, sirviéndole el auto de ejecución de sentencia de título ejecutivo para el cobro del monto determinado por el TCP.

Adicionalmente, respecto al monto mínimo de la indemnización de perjuicios, en el caso del derecho comparado, se prevé un criterio mínimo para considerar la cuantía a la que vaya a ascender: la indemnización deberá resarcir al reclamante, cuanto menos, de los gastos ocasionados por la preparación de la oferta o la participación en el procedimiento de contratación. ${ }^{87}$ Fuera interesante considerar algún es-

${ }^{87}$ El caso español. Artículo 48.2 del Decreto Legislativo n. ${ }^{\circ}$ 3/2011 de 14 de noviembre, por el que se aprueba el "Texto refundido de la ley de contratos del sector público". 
tándar semejante en el caso chileno, que pueda satisfacer mínimamente al licitador perjudicado por la no adjudicación del contrato, en los casos en los que se determinase la concurrencia de una ilegalidad o arbitrariedad en el procedimiento licitatorio.

Con las previsiones legales actuales y en base a una interpretación extensiva, si el TCP está facultado conforme al inciso $2^{\circ}$ del artículo 26 de la Ley de Compras para tomar "las medidas que sean necesarias para restablecer el imperio del derecho", bien podría entrar a conocer directamente del monto indemnizatorio que le correspondería al demandante, en su caso. Lo anterior, quizá, más que una modificación legal de las competencias del tribunal, requeriría una evolución jurisprudencial.

iii) Conocimiento sobre penalizaciones y multas

También cabe tener en cuenta ${ }^{88}$ que el TCP no conoce de los efectos derivados del incumplimiento contractual del proveedor que generen una penalización al contratista o al ente público que contrató; $; 9$ o inclusive incumplimientos acontecidos en la fase de licitación, en casos en los que, por ejemplo, una determinada entidad licitadora, declaró desierta la licitación y perjudicó a un licitante. ${ }^{90}$ En consecuencia, el conocimiento sobre la imposición de penalizaciones y multas habidas en el contexto de la licitación, por razones de especialidad también deberían ser conocidas por el TCP.

\section{PROPUESTAS RELATIVAS AL PROCEDIMIENTO ANTE EL TCP}

Por último, cabe referirse a cuestiones sobre el proceso ante este tribunal, al que se le aplica el escueto régimen previsto por la Ley de Compras y, supletoriamente, el Código de Procedimiento Civil (en ade426.

${ }^{88}$ Como observan Lara y García-Huidobro, “Aspectos críticos de la solución”,

89 Art. 79 ter del Decreto n. ${ }^{\circ}$ 250, que aprueba el Reglamento de la Ley 19.886, de "Bases sobre contratos administrativos de suministro y prestación de servicios". Este artículo fue introducido por el Decreto 1410 del Ministerio de Hacienda, que modifica el anterior. Diario Oficial, 12 de mayo de 2015.

90 Ver las sentencias: i) "Sergio del Rosario Morales con Dirección de Vialidad Región de Atacama”, 2006; ii) "Eurosolutions E.I.R.L. con Servicio Médico Legal", 2007; iii) "Instituto Nacional de Seguridad Integral y Desarrollo de Chile con Hospital Clínico San Borja Arriarán”, 2008. 
lante, CPC). El esquema procedimental que se sigue ante el TCP es el siguiente: ${ }^{91}$

i) Presentación de demanda y plazo

Cualquier licitador con un interés actualmente comprometido en el procedimiento podrá interponer, en el plazo de diez días hábiles desde la toma de conocimiento del acto u omisión que estime impugnable o desde su publicación, la demanda ante el TCP. Se establece un plazo de cinco días para subsanar aquellos defectos que el tribunal estime inadmisibles.

ii) Informe del organismo público que corresponda

Este informe deberá presentarse en el plazo fatal de diez días hábiles tras la recepción del contenido íntegro de la demanda, para informar acerca de lo impugnado.

iii) Suspensión potestativa del procedimiento de licitación

El TCP ostenta esta facultad en caso que concurra a su juicio lo siguiente: apariencia de buen derecho en que se funde el demandante en su demanda; gravedad de la ilegalidad o arbitrariedad imputada; y los elementos que miren al interés de la comunidad, por ejemplo, si el contrato ya se encontrase en ejecución o existe la urgencia de lo licitado. ${ }^{92}$

iv) Recepción a prueba de la causa y facultad de adoptar diligencias para mejor resolver

Se dispone un plazo de diez días hábiles, más diez días hábiles adicionales para el caso que haya que cumplir con alguna de las diligencias que ordene el TCP, de las que se encuentran en el artículo 159 del CPC. Ambos se sustancian en ramo separado y no suspenden el curso del juicio principal.

v) Sentencia definitiva

La sentencia definitiva deberá dictarse dentro del plazo de diez días desde la fecha de resolución que cita a las partes a oír sentencia, sin que quepa la posibilidad de presentar escritos o pruebas adicionales. El pronunciamiento se extenderá a la declaración —en su caso- de la ilegalidad o arbitrariedad cometidas en la licitación correspondiente, además de ordenar, si corresponde, las medidas necesarias para el restablecer el imperio del derecho.

${ }^{91}$ Artículos 24, 25, 26 y 27 de la Ley de Compras. Para una descripción más detallada, véase Vergara, "Tribunal de Contratación Pública", 365-367.

92 Criterios señalados por el presidente actual del órgano, que no se encuentran positivizados en la ley. Arévalo, "Rol del juez", 7. 
Contra dicha sentencia, sólo cabe recurso de reclamación ante la Corte de Apelaciones de Santiago, a interponer dentro del plazo de cinco días hábiles desde la notificación de la sentencia. Contra la que dicte la Corte, sólo podría caber — por vía extraordinaria- recurso de queja ante la Corte Suprema.

Fijado el esquema anterior, cabe observar los siguientes aspectos críticos. $^{93}$ Observando las propuestas efectuadas, especialmente en la mesa de trabajo, se aprecia un esfuerzo considerable para completar, mejorar y ampliar la regulación de las cuestiones procedimentales ante el tribunal. Ello venía siendo necesario vista la constante crítica sobre la parquedad con la que se regulaba el procedimiento ${ }^{94}$ — más allá de la escueta regulación que actualmente norma al $\mathrm{TCP}$ - . Al respecto, nuestras propuestas van dirigidas a los puntos que a continuación señalamos:

\subsection{Aplicación supletoria del Código de Procedimiento Civil}

Considerando la parquedad con la que se regula el procedimiento ante el TCP, ${ }^{95}$ para muchas actuaciones es necesario recurrir al Código de Procedimiento Civil (CPC) como norma supletoria, la que no siempre es adecuada si tiene en cuenta que el artículo 27 de la Ley de Compras establece la necesidad de aplicar las reglas de aquélla que resulten conformes a la naturaleza breve y sumaria del procedimiento. Al respecto, cabe señalar dos inconvenientes: ${ }^{96}$

i) Inadecuada aplicación del CPC sobre duración de los incidentes

Respecto a los incidentes, el inciso $7^{\circ}$ del artículo 25 de la Ley de Compras únicamente indica que tales se substanciarán por ramo separado y que no suspenderán el curso del juicio. La crítica subyace en la duración y el periodo probatorio de los incidentes de acuerdo al artículo 90 del CPC: el plazo es de ocho días, pudiendo ser objeto de ampliación si el TCP lo estima conveniente. Se destaca que dicho plazo es prácticamente igual al del juicio principal (diez días). Sin el establecimiento de un plazo más adecuado a la naturaleza breve y sumaria del procedimiento ante el TCP, dichos incidentes pudieran ocasionar más dilaciones que las regulares.

\footnotetext{
${ }^{93}$ Varios de ellos recogidos por diversos autores que iremos citando respectivamente.

${ }^{94}$ Aspecto criticado por su actual presidente. Arévalo, "Rol del juez", 6.

${ }^{95}$ Aspecto también criticado por su actual presidente. Arévalo, "Rol del juez", 6.

${ }^{96}$ Vergara, "Tribunal de Contratación Pública", 367-368.
} 
ii) Aplicación supletoria de las reglas del juicio ordinario

El proceso ordinario (de conocimiento lato) es radicalmente opuesto al procedimiento ante el TCP (de naturaleza breve y sumaria), por lo que la aplicación supletoria de las reglas de los juicios ordinarios resultará muchas veces inadecuada, tal como advierte por ejemplo el tribunal en referencia a la valoración de la prueba, la cual estima que no debiera estar tasada por ley, sino que fuera apreciable de acuerdo a las reglas de la sana crítica. ${ }^{97} \mathrm{El}$ TCP deberá ponderar la aplicación de estas normas caso por caso.

\subsection{La suspensión del procedimiento}

La suspensión del procedimiento, tal como está contemplada en el inciso $2^{\circ}$ del artículo 25 , sólo puede decretarla el propio tribunal, mediante resolución fundada, respecto del procedimiento en el que recae la acción de impugnación. ${ }^{98}$

Dicha institución resulta ser un arma de doble filo: en casos en los que no haya una necesidad perentoria de adjudicar un contrato para la urgente prestación del servicio o del suministro, ${ }^{99}$ resultaría lógico su decreto para evitar que los efectos de un procedimiento presuntamente viciado, pueda traspasar las barreras de la legalidad, por contener defectos de forma o fondo. No obstante, en situaciones de urgencia, ¿sería éste un hecho suficientemente justificable como para permitir que el procedimiento avance, y que, de afirmarse su ilegalidad o arbitrariedad, se llegue a ejecutar un contrato ab initio nulo, o cuanto menos anulable?

Esto último resulta criticable, ${ }^{100} \mathrm{y}$, desde la perspectiva de la declaración formal de ilegalidad o arbitrariedad, lo que cabe reprochar de forma especialmente enfática. ${ }^{101}$ En este último sentido, el TCP se

${ }^{97}$ Arévalo, "Rol del juez", 11.

${ }^{98}$ La Ley de Compras no establece que pueda solicitarse a instancia del demandante, si bien, como aclaró el tribunal, es constante la petición de suspensión por parte de éstos. Tribunal de Contratación Pública, Primera cuenta pública, 4.

${ }^{99}$ Causal del artículo 8 letra c de la Ley de Compras: "casos de emergencia, urgencia o imprevisto, calificados mediante resolución fundada del jefe superior de la entidad contratante".

${ }^{100}$ Lara y García-Huidobro, “Aspectos críticos de la solución”, 423; Vergara, "Tribunal de Contratación Pública", 371 y 373 (señala la necesidad de hacer una buena combinación de las medidas para restablecer el imperio del derecho y la cautelar suspensiva); Escanilla, "El Tribunal de Contratación", 117-118.

${ }^{101}$ En concordancia con: Concha, "Crítica a la falta", 287-378. 
niega a hacer valer los efectos anulatorios y retroactivos (en su caso) que debería acarrear la declaración de ilegalidad o arbitrariedad de la licitación pública respectiva, sobre la base de diferentes líneas jurisprudenciales que éste ha mantenido en el tiempo, reconociéndole al demandante damnificado, como solución a la ineficacia de tales efectos, el derecho a solicitar una indemnización. Las líneas jurisprudenciales son de tres órdenes.

En el primero, el TCP se niega a declarar ineficaz el contrato, en consideración al interés público o general comprometido en la contratación y los derechos adquiridos de a quien se le adjudicó el contrato, señalando respecto a esto último, que mal pueden haberse creado derechos adquiridos si se constata la ilegalidad del proceso de licitación. ${ }^{102}$

En el segundo, sobre la base de argumentos tales como que resultase inoficioso declarar la nulidad en tanto que el contrato objeto de la licitación impugnada se hubiese ejecutado, o bien, si éste se hubiera ejecutado en el momento de la ejecutoriedad de la sentencia definitiva de ilegalidad. ${ }^{103}$

En la última tendencia jurisprudencial, el TCP sujeta a condición la cuestión de la eficacia del contrato. Se declara la ilegalidad de éste y se priva de efectos al acto impugnado, pero establece una condición a su declaración: en caso que se demuestre el cumplimiento íntegro del contrato, y no se pudieran materializar los derechos de la demandante, se le reconoce el derecho a la indemnización. Inclusive, se ha utilizado una fórmula más genérica: "si por cualquier motivo de orden administrativo o legal, no pudiese llevarse a efecto lo dispuesto en lo resolutivo en este fallo se reconoce el derecho a indemnización". ${ }^{104}$

¿Deberían prevalecer el interés público o los derechos (supuestamente) adquiridos frente al respeto hacia la legalidad?

En definitiva, para evitar este tipo de efectos perniciosos, se hace necesario un mejor desarrollo de la medida cautelar estableciendo requisitos de fondo que permitan al TCP apreciar de mejor manera el periculum in mora que afecta al solicitante, lo cual se traduciría en adelantar la entrega de los antecedentes que en principio la parte demandante tiene reservada para el periodo probatorio.

102 Ibídem, 290-291. Damos por reproducida la ejemplificación de sentencias que cita.

${ }^{103}$ Ibídem, 291, n. 49.

${ }^{104}$ La clasificación en Concha, "Crítica a la falta”, 292-293. Ibídem, n. 49. 


\subsection{Informe que debe emitir el órgano licitador al tribunal}

La ley omite indicar la consecuencia en caso de que el órgano licitador no informe a tiempo al tribunal. Se ha indicado que el TCP podría hacer uso de las medidas para mejor resolver (art. 25 de la Ley de Compras) en caso que tuviese dudas sobre la posición del ente licitador. ${ }^{105}$

\subsection{Medidas adoptables por el TCP106}

Cabe distinguir dos tipos de medidas que el tribunal puede adoptar: las primeras, durante el proceso, encaminadas a la mejor resolución de la contienda (art. 25 inciso $6^{\circ}$ de la Ley de Compras); y las segundas, adoptables con ocasión de la dictación de sentencia para restablecer el imperio del derecho (art. 26 inciso $1^{\circ}$ de la Ley de Compras). Se desarrollan a continuación:

\section{i) Diligencias para mejor resolver}

Respecto de esta medidas, se ha indicado que no se limitan únicamente a aquellas previstas por el artículo 159 del Código de Procedimiento Civil (CPC), sino que la ley habilita al TCP a poder hacer uso de "otras diligencias encaminadas a comprobar los hechos controvertidos", por lo que el órgano jurisdiccional cuenta con un amplio abanico de posibilidades para esclarecer mejor los puntos discutidos en el libelo correspondiente.

ii) Medidas para restablecer el imperio del derecho

En relación a estas medidas, pueden señalarse dos críticas: son potestativas para el tribunal y la ley no establece un listado de posibilidades ni ejemplo de ellas, quedando exclusivamente a criterio del tribunal. ${ }^{107}$ La Corte Suprema, en un fallo, parece entender que estas

105 Vergara, "Tribunal de Contratación Pública", 371.

106 Siguiendo en este apartado a Vergara, "Tribunal de Contratación Pública”, 372-373.

107 En Lara y García-Huidobro, “Aspectos críticos y desafíos”, 139, señalan la consecuencia práctica de este segundo punto: “(...) al no reconocer la ley las medidas que el Tribunal de Contratación Pública puede dictar para reestablecer el imperio del derecho, en la práctica sus pronunciamientos suelen ser más bien declarativos y no constitutivos de derechos para las partes. En caso contrario, si el tribunal decide adoptar alguna medida tendiente al restablecimiento del derecho, la naturaleza y entidad de ésta, quedará entregada a su entero criterio". 
medidas pueden aplicarse de forma amplia, y que incluso podrían alcanzar a incorrecciones jurídicas detectadas durante el proceso de licitación. ${ }^{108}$

En síntesis, cabe un mayor desarrollo de las medidas que puede dictar el TCP para promover coherentes resoluciones de los casos, así como de aquellas encaminadas a restablecer el imperio del derecho.

En el caso del pronunciamiento sobre la indemnización (entendiéndose como medida para el restablecimiento del imperio del derecho), sería interesante, como se indica supra, prever expresamente en el cuerpo legal que en el mismo procedimiento el TCP pueda conocer sobre el monto indemnizatorio solicitado con motivo de la vulneración de sus derechos. Como mínimo, tal como apuntaba el propio presidente del TCP, ${ }^{109}$ se debiera incorporar en la ley una previsión para impedir que, en un eventual juicio de indemnización de perjuicios seguido por el proveedor en contra del organismo público, se vuelvan a discutir los hechos fijados en la correspondiente sentencia dictada por el TCP.

\subsection{Mejora de la regulación sobre la medida cautelar de suspensión}

Con la situación actual, si ante la detección de una infracción en cualquier fase de la licitación, el procedimiento no se suspendiera y siguiera hasta la perfección del contrato o más allá, en nada quedará la posible declaración de ilegalidad o arbitrariedad del acto impugnado, ya que a resultas de tan avanzado estado del procedimiento el TCP suele inclinarse a no anular ni retrotraer el procedimiento; ello, sin perjuicio del monto indemnizatorio que le pudiera corresponder al perjudicado.

Como señalamos más arriba, ha sido objeto de crítica la no suspensión del procedimiento cuando se está ante licitaciones no urgentes, en las que se aprecia la apariencia de buen derecho del demandante. De manera semejante, como también se señalaba, la no suspensión del procedimiento ante licitaciones urgentes en las que se pudiera acabar apreciando una ilegalidad o arbitrariedad, y que a su pesar, se adjudica-

108 "Montenegro con Ilustre Municipalidad de Santiago y Parquímetros y Controles Interparking Limitada", 2012.

${ }^{109}$ Ver Arévalo, "Rol del juez", 11. 
se el contrato a un tercero, ${ }^{110}$ partiendo de un procedimiento viciado en su formación, resulta igualmente criticable.

La mesa de trabajo al respecto propone, uno, extender la facultad de suspender los efectos derivados de los actos u omisiones de la administración durante la ejecución de los contratos administrativos; dos, en caso de licitaciones, ordenar al organismo licitante que se abstenga de ejecutar todos los actos y contratos que sean consecuencia o deban celebrarse con motivo de la licitación; y, tres, informar a la Dirección de Compras para que ésta, a través del sistema de información, dé a conocer que en la licitación correspondiente se dedujo acción judicial de impugnación (acción que a propósito, proponemos, pudiera también hacerse extensiva a la fase de ejecución del contrato, para informar a los usuarios afectados por las consecuencias que ello implicase).

Sin perjuicio de las consideraciones anteriores, creeríamos conveniente formular algunos mecanismos adicionales que optimicen el uso de la herramienta suspensiva. En verdad, la medida consistente en indemnizar al demandante perjudicado ante casos en que el tribunal declare la ilegalidad o arbitrariedad, si se hubiere perfeccionado el contrato administrativo, es acertada desde la perspectiva del interés particular afectado; pero desde la perspectiva pública quizá no sea la más adecuada: cabe no olvidar que el monto indemnizatorio que el órgano licitador deba abonarle al demandante proviene del erario público. Una mejor regulación de la medida de suspensión pudiera ser favorable y conciliable con los dos intereses en juego, ${ }^{111}$ sin perjuicio de establecer, mediante una fórmula siquiera genérica, cuando debiese proceder obligatoriamente la suspensión.

\subsection{Establecimiento de medidas para el caso de no cumplimiento de lo ordenado en la sentencia del TCP}

Cabría prever algún tipo de medidas que compelan al órgano licitador, cuyos actos de la licitación hayan sido impugnados ante el TCP,

110 Recurriendo a los datos proporcionados por el TCP en su sitio web, al menos desde el 28 de septiembre de 2010 hasta el 31 de diciembre de 2013, el acto más impugnado fue la adjudicación (58 por ciento); con mayor razón cabe trabajar en una mejora de la regulación actual de la suspensión que le aporte eficacia a la ulterior resolución del tribunal.

${ }^{111}$ Nos remitimos a lo más señalado arriba en relación con la medida suspensiva contemplada para el caso español. 
para que cumpla con lo ordenado en la sentencia. La actual previsión normativa nada dice al respecto, salvo la posibilidad de que el TCP, con ocasión de la sentencia definitiva, ordene las medidas que sean necesarias para restablecer el imperio del derecho.

En efecto, según declaraba el actual presidente del TCP: “(...) muchas veces cuando la obra o el servicio ya están ejecutados, sólo cabe declarar la ilegalidad y dar derecho al actor a demandar en sede civil la indemnización respectiva. Con todo, es usual que se declare la nulidad del acto y se ordene retrotraer la licitación al estado anterior al que se dictó el acto declarado ilegal y arbitrario. Cuando la entidad licitante cumple no hay problema, pero cuando no lo hace o bien sólo cumple formalmente, es que aparece el problema de cómo se ejecuta la sentencia. Hemos resuelto caso a caso, tomando en cuenta los factores que aluden a la especial naturaleza de estos conflictos y las consecuencias jurídicas y sociales de la decisión". ${ }^{112}$

Al respecto sería de utilidad prever algún mecanismo para el caso que la entidad licitante no cumpla lo requerido por el tribunal, como, por ejemplo, si no obedece dentro de un determinado plazo, el TCP estuviera facultado para la imposición de multas coercitivas que inciten al cumplimiento de lo acordado, las que podrán ser impuestas también al funcionario encargado de ejecutar la sentencia.

\subsection{Previsión de penalizaciones en caso que se hubiere ejercitado la acción de impugnación con temeridad o mala fe}

El inciso $3^{\circ}$ del artículo 24 de la Ley de Compras prevé una aparentemente amplia legitimación activa para la interposición de la acción de impugnación - - "podrá ser interpuesta por toda persona natural o jurídica, que tenga un interés actualmente comprometido en el respectivo procedimiento administrativo de contratación"-, lo que sin duda garantiza el derecho a la tutela judicial en un campo de tanta importancia como las compras públicas. Como se ha indicado, "puede sostenerse que el tribunal se diseña como garantía jurisdiccional, destinada a proteger el interés privado del proveedor afectado por una ilegalidad/ arbitrariedad del organismo público que convoca a la licitación, pero

${ }^{112}$ Arévalo, "Rol del juez", 10-11. 
también destinada a proteger el interés público para que resulte elegida la mejor oferta por la administración, seleccionando al co-contratante más idóneo para el Estado". ${ }^{113}$

En efecto, cabe tener presente la dicotomía de intereses que conviven en el ámbito de las licitaciones públicas. Por un lado, el proveedor estará interesado en que, en la licitación a la que vaya a postular su oferta, se respeten tanto la normativa aplicable, como también la correcta valoración de su propuesta en comparación con otras. Por otro lado, existe el interés público latente de que también se cumpla a cabalidad con las reglas previstas, junto con que se proceda adecuadamente a la adjudicación de la oferta más ajustada a la necesidad pública por la cual se abrió la licitación.

Pudiera ocurrir que, al amparo de la legitimación activa del artículo 24 de la Ley de Compras, un proveedor participante viese espontáneamente la oportunidad de paralizar el procedimiento e intentar, por medio de argumentos poco razonables o inclusive temerarios, convencer al tribunal de que su propuesta es la que mereciera ser adjudicataria de la licitación — en caso que lo impugnado fuera la adjudicación-.

Los principios que se predican de la contratación pública y la privada, así como los intereses involucrados, son diversos. Como indica Cassagne, en la contratación pública, el acuerdo de voluntades con el contratista privado se caracteriza uno, por perseguir una finalidad inmediata de interés público propia de la función administrativa; dos, por contener un régimen típico de derecho administrativo con prerrogativas de poder público $\mathrm{y}$, tres, por un sistema de selección fundado en los principios de publicidad, igualdad y concurrencia. ${ }^{114}$

Entonces, los intereses en juego existentes en la licitación demandan que se busque la mayor celeridad posible en el procedimiento, junto con la justa y adecuada adjudicación del contrato a la oferta que mejor se adapte las necesidades públicas.

Por lo anterior, no resulta aceptable que un determinado proveedor, siguiendo una conducta que rozase el abuso del derecho o la mala fe y con el propósito de sacar un provecho injustificado, interponga una de-

113 Ibídem, 4.

114 Juan Carlos Cassagne, "La contratación pública. Fronteras, tensiones e interrelación con el derecho privado en el nuevo escenario contractual", en Revista Derecho \& Sociedad 44 (2014): 18. 
manda que pueda eventualmente paralizar el procedimiento e irrumpirlo temerariamente, en perjuicio del resto de licitadores y del propio órgano licitante.

En consecuencia, estimaríamos oportuno la posibilidad de que se facultase al tribunal a que, si de las actuaciones practicadas y del expediente administrativo se demostrase que la demanda se interpuso con manifiesta actitud temeraria o de mala fe, en la sentencia que dicte pueda acordar la imposición de una multa al demandante, previendo un rango de montos más un criterio de graduación para su imposición, tomando en consideración el perjuicio ocasionado al órgano licitante así como a los restantes participantes de la licitación. ${ }^{115}$

\section{CONCLUSIONES}

Uno. El prototipo de justicia administrativa especializada que comenzó a implementarse en Chile en 2003, precisamente con la creación del Tribunal de Contratación Pública, pareciera haberse asentado como modelo singular en el que, a partir de varios tribunales especiales, se resuelven conflictos propios de materias específicas y técnicas como el medio ambiente, el derecho de la competencia, el sector eléctrico, la transparencia administrativa, los tributos e impuestos y, como el caso estudiado, la contratación pública.

Dichos tribunales están formados por profesionales expertos en los campos donde se generan las respectivas contiendas, y vienen dotados de unas competencias y potestades exclusivas, que les permiten entrar a conocerlas de forma especializada. Además, la tendencia hacia su autonomía institucional, junto con la referida especialización y la naturaleza breve y sumaria de los correspondientes procedimientos, son una garantía para los sujetos cuya tutela judicial reclaman.

Dos. En el caso del Tribunal de Contratación Pública, si bien cabe valorar positivamente el trabajo realizado hasta la fecha, atendiendo a este modelo de justicia especializada y garantista frente a la actuación de los tribunales ordinarios, que resuelven procesos de conocimiento

115 Este mecanismo se prevé en el caso español. Art. 47.5 del Decreto Legislativo 3/2011, de 14 de noviembre, por el que se aprueba el "Texto refundido de la ley de contratos del sector público". 
lato, sería necesaria la revisión de su actual regulación para dotar a dicho órgano de competencias más amplias, así como perfeccionar diversos aspectos de su configuración presente, que permitan dotar de mayor efectividad a la ejecutividad de sus sentencias. ${ }^{116}$

Tres. Varios autores, inclusive también algunos integrantes del Tribunal de Contratación Pública, a la luz de la actual normativa que lo regula, o bien a través del análisis de sus sentencias y actuaciones, coinciden en la necesidad de abordar modificaciones legales en tres campos específicos: i) su organización y funcionamiento (arts. 22 y 23 de la Ley de Compras); ii) su ámbito competencial (art. 24 de la Ley de Compras); y iii) el procedimiento que se sigue ante él (arts. 24 a 27 de la Ley de Compras), todo esto con el propósito de optimizar el funcionamiento y la operatividad de dicho órgano jurisdiccional.

Cuatro. Consideramos acertado, con carácter general, lo discutido y criticado hasta ahora respecto de la actual configuración y actuación del tribunal. Sin perjuicio de ello, en este trabajo hemos querido reflejar o reforzar otros aspectos adicionales que creemos pueden ser de utilidad al propósito de mejorar su regulación y práctica.

\section{BIBLIOGRAFÍA}

Arévalo Adasme, Álvaro. "Rol del juez en el proceso administrativo licitatorio". Discurso en el Seminario de Contratación Administrativa y Compras Públicas, celebrado el 28 de mayo de 2014 en la Facultad de Derecho de la Pontificia Universidad Católica de Chile. Disponible en http://www. tribunaldecompras.cl.

Bernal Blay, Miguel Ángel. "Aspectos orgánicos del recurso especial en materia de contratación pública en las comunidades autónomas". Cuadernos de Derecho Local 26 (2011): 7-26.

Bermúdez Soto, Jorge, ed. Perspectivas para la modernización del derecho de la contratación administrativa. Actas de las XI Jornadas de Derecho Administrativo. Valparaíso: Publicaciones de la Escuela de Derecho PUCV, 2016.

116 Conclusión a la que también llegan Lara y García-Huidobro, "Aspectos críticos y desafíos”, 2016, 149: “(...) fácil es comprender el gran desafío que se tiene por delante: el establecimiento de un adecuado mecanismo de solución de controversias que permita resolver los conflictos surgidos durante la relación contractual-administrativa con la necesaria especialización que la materia supone y la adecuada eficiencia que los tribunales ordinarios difícilmente podrían asegurar". 
Cassagne, Juan Carlos. "Actuales desafíos y clásicos dilemas de la contratación administrativa”. En Derecho administrativo. Innovación, cambio y eficacia. Libro de ponencias del sexto congreso nacional de derecho administrativo, 191-201. Lima: Thomson Reuters, 2014.

—. El contrato administrativo. Buenos Aires: Abeledo Perrot, 2009.

—. "La contratación pública. Fronteras, tensiones e interrelación con el derecho privado en el nuevo escenario contractual". Revista Derecho \& Sociedad 44 (2015): 15-21.

Concha Machuca, Ricardo. "Crítica a la falta de declaración de nulidad y a la consiguiente configuración de la eficacia del contrato público inválido soportado en un procedimiento ilegal". Revista de Derecho de la Pontificia Universidad Católica de Valparaíso XLVI (2016): 287-378.

Consejo Asesor Presidencial Contra los Conflictos de Interés, el Tráfico de Influencias y la Corrupción. Informe final. Santiago: 2015.

Dirección de Compras y Contratación Pública. Informe de recomendaciones. Comisión de Perfeccionamiento de las Compras Públicas. Santiago: Dirección de Compras y Contratación Pública, 2013.

. Informe final. Mesa de trabajo para la modificación de la Ley 19.886. Santiago: 2016.

Escanilla Abarza, Eduardo. "El Tribunal de Contratación Pública en Chile. Un análisis crítico propositivo". Derecho Público Iberoamericano 2 (2013): 103310 .

González-Varas Ibáñez, Santiago. "La normativa europea procesal de contratación pública y el sistema actual de recursos contractuales”. Revista Documentación Administrativa 288 (2010): 43-63.

Huepe Artigas, Fabián. "La facultad de la administración para poner término unilateral al contrato y su impugnación". En Perspectivas para la modernización del derecho de la contratación administrativa, editado por Bermúdez Soto, 99-126.

Lara Arroyo, José Luis \& Gabriel Bocksang Hola, coordinadores. Procedimiento administrativo y contratación pública. Estudios a diez años de la entrada en vigencia de las leyes 19.880 y 19.886. Santiago: Legal Publishing \& Thomson Reuters, 2013.

Lara Arroyo, José Luis \& Luis Eugenio García-Huidobro Herrera. “Aspectos críticos de la solución de controversias en la contratación administrativa bajo la Ley 19.886: El caso del Tribunal de Contratación Pública”. En Procedimiento administrativo y contratación pública, coordinado por Lara Arroyo \& Bocksang Hola, 405-448.

—. "Aspectos críticos y desafíos de la contratación administrativa bajo la Ley $\mathrm{N}^{\circ}$ 19.886". En Perspectivas para la modernización del derecho de la contratación administrativa, editado por Bermúdez Soto, 129-150.

Marín Vallejo, Urbano. "Vigencia actual de la invalidación de los actos administrativos". Revista de Derecho del Consejo de Estado 2 (2002): 1-9. 
Moderne, Frank. "La contratación pública en el derecho administrativo francés contemporáneo". En La contratación pública, editado por Juan Carlos Cassagne \& Enrique Rivero Yserrn, 253-274. Buenos Aires: Hammurabi, 2006.

Mora Allende, Carolina: "La protección de los particulares frente a la administración pública contratante: el caso del Tribunal de Contratación Pública". En Perspectivas para la modernización del derecho de la contratación administrativa, editado por Bermúdez Soto, 231-248.

Moraga Klenner, Claudio. Contratación administrativa. Santiago: Editorial Jurídica de Chile, 2010.

—. La actividad formal de la administración del Estado. Santiago: Abeledo Perrot, 2010.

Muñoz Chiu, Natalia. “Contratación administrativa”. Revista de Derecho 12 (2004): 9-11.

Nicólas Turrys, Jenny. "Contratación administrativa a través de convenios marco: naturaleza jurídica y aplicación práctica”. Revista de Derecho Administrativo Económico 20 (2015): 43-80.

__. "La declaración de inadmisibilidad de las ofertas en un proceso licitatorio". En Perspectivas para la modernización del derecho de la contratación administrativa, editado por Bermúdez Soto, 245-264.

OCDE. Contratación pública en Chile. Opciones de política para convenios marco eficientes e inclusivos. Estudios de la OCDE sobre gobernanza pública. París: Éditions OCDE, 2017.

. "Recomendación del consejo sobre contratación pública". 18 de febrero de 2015. Disponible en https://www.oecd.org/gov/ethics/OCDE-Recomendacionsobre-Contratacion-Publica-ES.pdf.

Olmos Carrasco, Felipe. "Aspectos orgánicos y competencia del Tribunal de Contratación Pública". En Procedimiento administrativo y contratación pública, coordinado por Lara Arroyo \& Bocksang Hola, 449-480.

Pardo García-Valdecasas, Juan José. "El Tribunal Administrativo Central de Recursos Contractuales”. Revista Documentación Administrativa 288 (2010): $19-41$.

Pérez Gutiérrez, Dorothy. "Extensión del ámbito de aplicación de la ley de compras públicas, un desafío pendiente". En Procedimiento administrativo y contratación pública, coordinado por Lara Arroyo \& Bocksang Hola, 481508.

Pinilla Rodríguez, Francisco. "Los fundamentos generales de los poderes de ordenación en el contrato administrativo". En Perspectivas para la modernización del derecho de la contratación administrativa, editado por Bermúdez Soto, 275-286.

Ruiz Ibáñez, Andrés. "Límites a la facultad para establecer sanciones en los contratos de la ley 19.886". En Perspectivas para la modernización del derecho de la contratación administrativa, editado por Bermúdez Soto, 287294. 
Tornos Mas, Joaquín. "Los tribunales independientes para la resolución de los recursos administrativos en materia de contratos del sector público". En Derecho administrativo y regulación económica. Liber amicorum Gaspar Ariño Ortiz, coordinado por Juan Miguel de la Cuétara Martínez, José Luis Martínez López-Muñiz \& Francisco J. Villar Rojas. Madrid: La Ley, 2011. 805-826.

Tribunal Administrativo Central de Recursos Contractuales. Memoria de actividades, año 2016. Madrid: Tribunal Administrativo Central de Recursos Contractuales, Ministerio de Hacienda y Función Pública, 2017.

Tribunal de Contratación Pública. Primera cuenta pública. 2012. Disponible en http://www.tribunaldecompras.cl.

Vásquez Santander, Yuri Antonio \& Maximiliano Alfredo Koch Chacón. Institucionalidad, procedimiento y jurisprudencia del Tribunal de Contratación Pública. Análisis jurisprudencial desde su establecimiento hasta la actualidad. Memoria para optar al grado de licenciado en ciencias jurídicas y sociales. Santiago: Universidad de Chile, 2014.

Vergara Blanco, Alejandro. "Autoridades independientes y ordenación de la contratación administrativa". En Contratos públicos, problemas, perspectivas y prospectivas. XVIII Jornadas internacionales de Derecho Administrativo. Bogotá: Universidad Externado de Colombia, 2017.

_. "El nuevo paradigma de jurisdicción administrativa pluriforme e híper especializada. Crónica de una espera, como la de Godot". En Anuario de Derecho Público UDP, 269-292. Santiago: Universidad Diego Portales, 2014.

_. "La tendance actuelle du droit chilien pour une juridiction administrative hyper-spécialisée”. En Mélanges en l’honneur de Pierre Bon, 126-140. París: Éditions Dalloz, 2014.

—. "Los jueces en la era del derecho democrático. Especialización y principios, en la superación del activismo y la deferencia". Temas de la Agenda Pública 83 (2015): 12. Centro de Políticas Públicas UC.

—. "Tribunal de Contratación Pública. Bases institucionales, organización, competencia y procedimiento". Revista de Derecho de la Pontificia Universidad Católica de Valparaíso XLVI (2016): 347-378.

VV.AA. Patologías de la contratación pública. Madrid: Gómez-Acebo \& Pombo Abogados, 2014.

\section{Normativa citada}

1. España

Directiva 2004/18/CE de 30 de abril de 2004 y 31 de marzo de 2004. "Coordinación de los procedimientos de adjudicación de los contratos públicos de obras, de suministro y de servicios". Parlamento Europeo y del Consejo, Unión Europea.

Directiva 2007/66/CE de 20 de diciembre de 2007 y 11 de diciembre de 2007. "Se modifican las Directivas 89/665/CEE y 92/13/CEE del Consejo en lo que 
respecta a la mejora de la eficacia de los procedimientos de recurso en materia de adjudicación de contratos públicos”. Parlamento Europeo y Consejo, Unión Europea.

Ley 30/2007 de 31 de octubre de 2007. "Contratos del sector público”. España.

Ley 34/2010 de 9 de agosto de 2010. "Modificación de las Leyes 30/2007, de 30 de octubre, de contratos del sector público, 31/2007, de 30 de octubre, sobre procedimientos de contratación en los sectores del agua, la energía, los transportes y los servicios postales, y 29/1998, de 13 de julio, reguladora de la jurisdicción contencioso-administrativa para adaptación a la normativa comunitaria de las dos primeras". España.

Real Decreto Legislativo 3/2011 de 16 de noviembre de 2011. "Texto refundido de la Ley de contratos del sector público". España.

Ley 40/2015 de 2 de octubre de 2015. "Régimen jurídico del sector público". España.

\section{Chile}

Constitución Política de la República de Chile de 1980, de 22 de septiembre de 2005. República de Chile.

Ley 18.695 de 26 de julio 2006. "Orgánica constitucional de municipalidades”. República de Chile.

Ley 19.886 de 30 de julio 2003. "Establece bases sobre contratos administrativos de suministro y prestación de servicios". República de Chile.

Ley 20.322 de 27 enero de 2009. "Fortalece y perfecciona la jurisdicción tributaria y aduanera". República de Chile.

Ley 20.883 de 2 de diciembre de 2015. "Otorga reajuste de remuneraciones a los trabajadores del sector público, concede aguinaldos que señala, y concede otros beneficios que señala". República de Chile.

Ley 20.886 de 18 de diciembre 2015. "Modifica el Código de Procedimiento Civil para establecer la tramitación digital de los procedimientos judiciales". República de Chile.

Decreto 250 de 2004. "Aprueba el reglamento de la Ley 19.886, de Bases de Contratos Administrativos de Suministro y Prestación de Servicios". Ministerio de Hacienda.

Decreto 1.410 de 2015. "Modifica el Reglamento de la Ley 19.886, de Bases de Contratos Administrativos de Suministro y Prestación de Servicios". Ministerio de Hacienda.

Auto acordado de la Corte Suprema de 11 de marzo de 2011, texto refundido, Acta n. ${ }^{\circ} 16-2011$.

Acta n. ${ }^{\circ}$ 7-2011 de la Corte Suprema, de 7 de marzo de 2011.

Decreto Legislativo $3 / 2011$, de 14 de noviembre, por el que se aprueba el texto refundido de la Ley de Contratos del Sector Público. Boletín Oficial del Estado. 16 de noviembre de 2011. 


\section{Jurisprudencia citada}

\section{Jurisprudencia judicial}

Montenegro Peña, Maximiliano con Municipalidad de Santiago y Parquímetros y Controles Interparking Limitada. Corte Suprema, 2 de agosto 2012, Rol 11052012 .

\section{Jurisprudencia del TCP}

"Ely Lilly de Chile Limitada con Central de Abastecimiento del Sistema Nacional de Servicios de Salud”. TCP, 30 de abril 2005, Rol 2-2005.

"Sergio del Rosario Morales con Dirección de Vialidad Región de Atacama". TCP, 9 de noviembre 2006, Rol 85-2006.

"Eurosolutions E.I.R.L. con Servicio Médico Legal”. TCP, 26 junio 2007, Rol 322007.

"Instituto Nacional de Seguridad Integral y Desarrollo de Chile con Hospital Clínico San Borja Arriarán”. TCP, 11 de enero 2008, Rol 6-2008.

"Diálisis Renca Limitada con Dirección de Compras y Contratación Pública". TCP, Rol 91-2008.

"Laboratorio Chile S.A. con Central de Abastecimiento del Sistema Nacional de Servicios de Salud". TCP, 12 de junio 2009, Rol 28-2008.

"Grupo Bios con Servicio de Salud Metropolitano Sur Oriente". TCP, 29 octubre 2009, Rol 115-2009.

“Ingeniería y Construcción Ricardo Rodríguez y Cía. con Dirección de Compras y Contratación Pública”. TCP, 16 de agosto 2011, Rol 125-2011.

“Ingeniería y Construcciones del Pacífico Limitada con Dirección de Aeronáutica Civil". TCP, 7 de mayo 2009, Rol 49-2007.

"Centro de Gestión Ambiental y Servicios Crecer Limitada con Ilustre Municipalidad La Granja”. TCP, 10 de agosto 2012, Rol 139-2012.

“Aseo y Servicios Industriales Limitada con Instituto de Previsión Social”. TCP, 14 de mayo 2013, Rol 58-2013.

"Inducien Instruments con Dirección General de Aguas". TCP, 9 de septiembre 2014, Rol 142-2013. 


\section{ANEXO}

Tabla comparativa de la regulación actual respecto de las propuestas de modificación a la Ley 19.886 tratadas por el Informe final de la mesa de trabajo ${ }^{117}$ :

\begin{tabular}{|c|c|c|}
\hline ASPECTO & REGULACIÓN ACTUAL & $\begin{array}{l}\text { PROPUESTAS DE } \\
\text { MODIFICACIÓN }\end{array}$ \\
\hline General & $\begin{array}{l}\text { El artículo } 22 \text { inc. 10 LBCA se refiere } \\
\text { únicamente a la denominación "Tri- } \\
\text { bunal de Contratación Pública". }\end{array}$ & $\begin{array}{l}\text { Se propone el reconocimiento } \\
\text { legal expreso del TCP como "ór- } \\
\text { gano jurisdiccional especial", ade- } \\
\text { más de reconocerles a sus abo- } \\
\text { gados integrantes el tratamiento } \\
\text { de jueces. }\end{array}$ \\
\hline \multirow{3}{*}{$\begin{array}{l}\text { Organización } \\
\text { y funciona- } \\
\text { miento }\end{array}$} & $\begin{array}{l}\text { El artículo } 22 \text { inc. } 20 \text { LBCA indica } \\
\text { que el número de titulares es de } 3, \\
\text { y se les exige, entre otros requisitos, } \\
\text { experiencia en la materia. }\end{array}$ & $\begin{array}{l}\text { Se propone aumentar de } 3 \text { a } 6 \\
\text { titulares, y tener experiencia es- } \\
\text { pecifica en contratación admi- } \\
\text { nistrativa. Se especifica que los } \\
\text { requisitos para acceder a ser juez } \\
\text { del tribunal son de carácter copu- } \\
\text { lativo. }\end{array}$ \\
\hline & $\begin{array}{l}\text { Del artículo } 1 \text { del auto acordado de } \\
\text { la Corte Suprema se desprende } \\
\text { que el tribunal sólo opera en una } \\
\text { sala. }\end{array}$ & $\begin{array}{l}\text { Se propone, mediante previsión } \\
\text { en la LBCA al respecto, que el } \\
\text { tribunal funcione regularmente } \\
\text { en } 2 \text { salas, y de forma extraordi- } \\
\text { naria en } 3 \text {, con tres integrantes } \\
\text { por cada sala. La suplencia sólo } \\
\text { podrá ser ejercida hasta un máxi- } \\
\text { mo de seis meses (como prevé } \\
\text { actualmente la ley), pero se es- } \\
\text { tablece la necesidad de proveer } \\
\text { el cargo con un titular al llegar al } \\
\text { citado término. } \\
\text { El TCP sesionará de lunes a vier- } \\
\text { nes, bajo una presidencia en cada } \\
\text { sala, y los acuerdos se adoptarán } \\
\text { en régimen de simple mayoria. }\end{array}$ \\
\hline & $\begin{array}{l}\text { El artículo } 22 \text { inc. 60 LBCA dispone } \\
\text { un régimen remuneratorio consis- } \\
\text { tente en el pago de la suma equi- } \\
\text { valente a un treintavo de la renta } \\
\text { del Grado IV (correspondiente a los } \\
\text { Ministros de la Corte de Apelacio- } \\
\text { nes) por cada sesión a la que asis- } \\
\text { tan, con un máximo de } 21 \text { sesiones } \\
\text { mensuales, y un tope de una sesión } \\
\text { diaria. }\end{array}$ & $\begin{array}{l}\text { Se propone fijar un régimen re- } \\
\text { muneratorio diferenciado para } \\
\text { jueces y suplentes, consistente en } \\
\text { una remuneración mensual base } \\
\text { a todo evento, complementada } \\
\text { por remuneraciones determina- } \\
\text { bles en base al número de sesio- } \\
\text { nes a que haya asistido el respec- } \\
\text { tivo miembro del tribunal. }\end{array}$ \\
\hline
\end{tabular}

${ }^{117}$ Ver nota 30. 


\begin{tabular}{|c|c|c|}
\hline \multirow[t]{3}{*}{$\begin{array}{l}\text { Organización } \\
\text { y funciona- } \\
\text { miento }\end{array}$} & $\begin{array}{l}\text { La ley no indica nada respecto a la } \\
\text { heterocomposición del tribunal. }\end{array}$ & $\begin{array}{l}\text { Se propone considerar la in- } \\
\text { tegración de profesionales de } \\
\text { otras disciplinas como las cien- } \\
\text { cias económicas o en materias } \\
\text { relacionadas con las tecnologías } \\
\text { de la información. Como conse- } \\
\text { cuencia del aumento de salas, } \\
\text { se incrementa la plantilla dota- } \\
\text { cional del tribunal y se le sujeta } \\
\text { a diversas disposiciones legales, } \\
\text { entre ellas, las correspondientes } \\
\text { a la probidad administrativa. } \\
\text { Asimismo se sugiere regular con } \\
\text { mayor detalle la figura y funcio- } \\
\text { nes del secretario del TCP. }\end{array}$ \\
\hline & $\begin{array}{l}\text { Actualmente nada se señala res- } \\
\text { pecto del régimen de dedicación de } \\
\text { los jueces titulares ni la edad máxi- } \\
\text { ma para ejercer jubilación. }\end{array}$ & $\begin{array}{l}\text { Se propone que los jueces titu- } \\
\text { lares tengan dedicación exclu- } \\
\text { siva, indicándose un régimen de } \\
\text { incompatibilidades al respecto, y } \\
\text { se establece la edad máxima de } \\
\text { jubilación a los } 75 \text { años. }\end{array}$ \\
\hline & $\begin{array}{l}\text { El artículo } 23 \text { inc. } 2 \text { L LBCA y dispo- } \\
\text { siciones concordantes del auto de } \\
\text { la Corte Suprema, indican que la } \\
\text { DCCP deba proveer al tribunal la } \\
\text { infraestructura, el apoyo técnico y } \\
\text { los recursos humanos y materiales } \\
\text { para éste. }\end{array}$ & $\begin{array}{l}\text { Se propone que la gestión admi- } \\
\text { nistrativa del tribunal correspon- } \\
\text { da a la Unidad Administradora de } \\
\text { los Tribunales Tributarios y Adua- } \\
\text { neros (ex. art. } 18 \text { Ley } 20.322 \text { ). En- } \\
\text { tre otras funciones, deberá reali- } \\
\text { zar provisión del inmueble en que } \\
\text { deba aquél funcionar, asi como la } \\
\text { ejecución de la administración fi- } \\
\text { nanciera del tribunal. }\end{array}$ \\
\hline \multirow[t]{2}{*}{ Competencia } & $\begin{array}{l}\text { El artículo } 24 \text { inc. } 20 \text { LBCA prevé } \\
\text { que la competencia procedimental } \\
\text { del TCP se extiende desde la apro- } \\
\text { bación de las bases de licitación } \\
\text { hasta la adjudicación del contrato, } \\
\text { ambas inclusive. }\end{array}$ & $\begin{array}{l}\text { La propuesta consiste en exten- } \\
\text { der la competencia del tribunal } \\
\text { para conocer de actos } u \text { omisio- } \\
\text { nes ilegales o arbitrarios, que se } \\
\text { materialicen durante la ejecución } \\
\text { de un contrato con organismos } \\
\text { públicos regidos por la LBCA, } \\
\text { hasta su extinción. En consecuen- } \\
\text { cia, también se amplía la legiti- } \\
\text { mación activa en la interposición } \\
\text { de la acción, respecto de los nue- } \\
\text { vos actores. }\end{array}$ \\
\hline & $\begin{array}{l}\text { De los incisos } 1 \text { - y } 20 \text { del artículo } 24 \\
\text { LBCA se desprende la no inclusión } \\
\text { dentro de la competencia objetiva } \\
\text { del tribunal, para el conocimiento } \\
\text { de los procedimientos de trato di- }\end{array}$ & $\begin{array}{l}\text { Se propone que el tribunal pueda } \\
\text { conocer de la acción de impug- } \\
\text { nación dirigida contra actos u } \\
\text { omisiones, ilegales o arbitrarios, } \\
\text { ocurridos durante la tramitación }\end{array}$ \\
\hline
\end{tabular}




\begin{tabular}{|c|c|c|}
\hline \multirow{2}{*}{ Competencia } & $\begin{array}{l}\text { recto y el procedimiento de gran- } \\
\text { des compras llevadas a cabo a tra- } \\
\text { vés de convenio marco. }\end{array}$ & $\begin{array}{l}\text { de estos dos procedimientos es- } \\
\text { peciales de contratación. En el } \\
\text { caso del convenio marco, aquellos } \\
\text { procedimientos que superen las } \\
1.000 \text { UTM. Se añaden también } \\
\text { los procedimientos seguidos ante } \\
\text { la DCCP relativos al registro de } \\
\text { contratistas del artículo } 16 \text { LBCA } \\
\text { (cuyos contratistas, además, } \\
\text { pasan a ser legitimarios activos } \\
\text { para la interposición de la acción). }\end{array}$ \\
\hline & $\begin{array}{l}\text { El articulo } 26 \text { inc. 1 LBCA faculta } \\
\text { al TCP para dictar, con ocasión de } \\
\text { la sentencia definitiva correspon- } \\
\text { diente, las medidas que sean nece- } \\
\text { sarias para restablecer el imperio } \\
\text { del derecho, entre las que se en- } \\
\text { cuentran, de acuerdo a su práctica, } \\
\text { el otorgamiento de una indemni- } \\
\text { zación al demandante cuyas pre- } \\
\text { tensiones procesales, pese haber } \\
\text { estado reconocidas en sentencia, } \\
\text { no pudieran materializarse por es- } \\
\text { tar el contrato ya perfeccionado, en } \\
\text { avanzada ejecución, o terminado. }\end{array}$ & $\begin{array}{l}\text { Prever que el tribunal civil com- } \\
\text { petente que conozca de la in- } \\
\text { demnización de perjuicios, deba } \\
\text { fundar su fallo en las conductas, } \\
\text { hechos y calificación jurídica de } \\
\text { los mismos, establecidos en la } \\
\text { sentencia del TCP, y tramitarlo } \\
\text { conforme las reglas establecidas } \\
\text { para el procedimiento sumario } \\
\text { del juicio ordinario. Se sujetan al } \\
\text { plazo de prescripción de cuatro } \\
\text { años, las acciones civiles deriva- } \\
\text { das de la acción de impugnación } \\
\text { desde que se encuentre ejecuto- } \\
\text { riada la sentencia definitiva. }\end{array}$ \\
\hline \multirow[t]{2}{*}{ Procedimiento } & $\begin{array}{l}\text { El artículo } 25 \text { LBCA no indica qué } \\
\text { pasa en el caso que, una vez recibi- } \\
\text { do el informe, el órgano demanda- } \\
\text { do oponga excepciones procesales } \\
\text { a la admisibilidad de la demanda. } \\
\text { En relación a los incidentes, única- } \\
\text { mente señala (inc. 7ํ) que no sus- } \\
\text { penderán el juicio y que se substan- } \\
\text { ciarán en ramo separado. }\end{array}$ & $\begin{array}{l}\text { Se propone reconocimiento ex- } \\
\text { preso de esta etapa, en la cual el } \\
\text { TCP resolverá estas cuestiones } \\
\text { previas a la brevedad. Contra la } \\
\text { resolución, procederá recurso de } \\
\text { reposición y apelación subsidiaria } \\
\text { con el solo efecto devolutivo. } \\
\text { En lo referente a los incidentes, } \\
\text { se prevé la posibilidad que pue- } \\
\text { dan ser resueltos de plano por el } \\
\text { tribunal, y que si bien, por regla } \\
\text { general, no suspenderán el curso } \\
\text { del juicio, si en el caso de las ex- } \\
\text { cepciones previas señaladas. }\end{array}$ \\
\hline & $\begin{array}{l}\text { De acuerdo al artículo } 25 \text {, inc. } 20 \\
\text { LBCA, acogida a tramitación la im- } \\
\text { pugnación, puede decretar, por re- } \\
\text { solución fundada, la suspensión del } \\
\text { procedimiento administrativo en el } \\
\text { que recae la acción de impugna- } \\
\text { ción. Dicha suspensión es posible, } \\
\text { de acuerdo a la práctica del tribu- } \\
\text { nal, hasta antes del perfecciona- } \\
\text { miento del contrato. }\end{array}$ & $\begin{array}{l}\text { La propuesta extiende esta posi- } \\
\text { bilidad cautelar a los efectos de } \\
\text { los actos u omisiones de la admi- } \\
\text { nistración durante la ejecución de } \\
\text { los contratos administrativos. } \\
\text { El efecto inmediato de dicha sus- } \\
\text { pensión será, en caso de licitacio- } \\
\text { nes, que el organismo licitante se } \\
\text { abstendrá de ejecutar todos los } \\
\text { actos y contratos que sean con- }\end{array}$ \\
\hline
\end{tabular}


De la LBCA, del auto acordado de la Corte Suprema, y de la práctica del tribunal, se desprende que la mayoría de los trámites y fases del procedimiento ante éste se llevan a cabo fisicamente.

Únicamente de la práctica del tribunal, se constata que puede utilizar el llamado a conciliación de las partes, previo a reanudar el procedimiento contencioso. secuencia o deban celebrarse con motivo de la licitación. En caso de ejecuciones contractuales, quedarán suspendidos todos los efectos jurídicos y materiales que resulten de los actos ejecutados y de las resoluciones dictadas en el desarrollo de las diversas etapas de cumplimiento del contrato sobre las que recae la suspensión.

Adicionalmente, se establece una medida cautelar consistente en informar a la DCCP para que ésta, a través del Sistema de Información, dé a conocer que en la licitación correspondiente se dedujo acción judicial de impugnación.

Se propone que el procedimiento judicial a tramitarse ante el TCP se desarrolle con carácter general de forma electrónica, conforme lo dispuesto por la Ley 20.886 .

Se propone un reconocimiento normativo expreso de la facultad del TCP de llamar a las partes a conciliación, asi como el establecimiento de unas reglas mínimas para su substanciación.

Actualmente, contra las resoluciones del tribunal no se prevé la posibilidad de interponer recurso alguno (salvo la sentencia definitiva).

En materia de prueba, el actual ar-
tículo 25 LBCA es parco en cuanto
a su regulación (inc. 3-6), remitién-
dose en todo lo no previsto al CPC
(art. 27 CPC).

La propuesta conduce a prever la posibilidad de impugnar, mediante recurso de reposición, las resoluciones pronunciadas por el TCP durante el procedimiento, a excepción de la sentencia definitiva.

En la propuesta se regula la prueba de forma más completa, introduciéndose varias medidas, a saber:

- En la prueba testifical, se admitirán hasta tres testigos, por cada uno de los hechos substanciales controvertidos.

- Reconocimiento expreso de la absolución de posiciones y de la 


\begin{tabular}{|c|c|c|}
\hline & & $\begin{array}{l}\text { posibilidad de apreciar la prueba } \\
\text { conforme las reglas de la sana } \\
\text { critica. } \\
\text { - Utilización del exhorto, por via } \\
\text { informática, para la rendición de } \\
\text { actuaciones probatorias, trámi- } \\
\text { tes, diligencias o notificaciones } \\
\text { que por orden del TCP hayan de } \\
\text { realizarse fuera de su asiento en } \\
\text { la ciudad de Santiago. }\end{array}$ \\
\hline Procedimiento & $\begin{array}{l}\text { El único recurso que está expre- } \\
\text { samente reconocido en la LBCA, } \\
\text { contra las sentencias del tribunal, } \\
\text { es el de reclamación ante la Corte } \\
\text { de Apelaciones de Santiago. En la } \\
\text { práctica también se permite, tras } \\
\text { la apelación, recurso extraordina- } \\
\text { rio de queja ante la Corte Supre- } \\
\text { ma. }\end{array}$ & $\begin{array}{l}\text { Se propone eliminar, tal como } \\
\text { actualmente está planteado, el } \\
\text { recurso de reclamación ante la } \\
\text { Corte de Apelaciones, abrien- } \\
\text { do la posibilidad directa de un } \\
\text { recurso de casación en el fondo } \\
\text { y en la forma ante la Corte Su- } \\
\text { prema, respetando una serie de } \\
\text { requisitos. } \\
\text { Contra las interlocutorias que } \\
\text { ponen término al juicio o hacen } \\
\text { imposible su continuación, serán } \\
\text { apelables, en subsidio del recur- } \\
\text { so de reposición. No serán ape- } \\
\text { lables las resoluciones dictadas } \\
\text { por el tribunal en etapa de cum- } \\
\text { plimiento del fallo. }\end{array}$ \\
\hline
\end{tabular}

